\title{
Physical and biological removal of Microcystin-LR and other water contaminants in a biofilter using coated sand composites
}

(i) The corrections made in this section will be reviewed and approved by journal production editor.

Pratik Kumar $^{\mathrm{a}}$, Hadji Rehab ${ }^{\mathrm{b}}$, Krishnamoorthy Hegde ${ }^{\mathrm{a}}$, Satinder Kaur Brar ${ }^{\mathrm{a}, \mathrm{c}, *}$ satinder.brar@ete.inrs.ca, Maximiliano Cledon ${ }^{\mathrm{d}}$, Azadeh Kermanshahi-pour ${ }^{\mathrm{e}}$, Sung Vo Duy ${ }^{\mathrm{f}}$, Sébastien Sauvéf, Rao Y. Surampallig

aINRS-ETE, Université du Québec, 490, Rue de la Couronne, Québec G1K 9A9, Canada

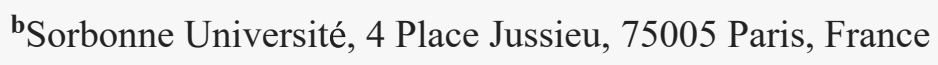

${ }^{\mathbf{c}}$ Department of Civil Engineering, Lassonde School of Engineering, York University, North York, Toronto M3J 1P3, Ontario, Canada

${ }^{\text {d} C I M A S ~(C O N I C E T, ~ U n C o m a, ~ R i o ~ N e g r o), ~ G u ̈ e m e s ~ 1030, ~ S a n ~ A n t o n i o ~ O e s t e, ~ R i o ~ N e g r o, ~ A r g e n t i n a ~}$

e'Biorefining and Remediation Laboratory, Department of Process Engineering and Applied Science, Dalhousie University, 1360 Barrington Street, Halifax, Nova Scotia B3J 1Z1, Canada

fDepartment of Chemistry, Université de Montréal, Montreal H3C 3J7, Canada

'Dept. of Civil Engineering, Univ. of Nebraska-Lincoln, N104 SEC PO Box 886105, Lincoln, NE 685886105, United States

*Corresponding author at: INRS-ETE, Université du Québec, 490, Rue de la Couronne, Québec G1K 9A9, Canada.

Editor: Jan Vymazal

\begin{abstract}
Sand as a filter media is often challenged by the presence of organics in the form of natural organic matter, metal ions, and various micropollutants in the source water. It is mainly due to the presence of limited active adsorption sites and low surface area that governs an ineffective adsorption potential of the sand material. Herein, graphitized sand was synthesized to tackle the above limitations using two sugar solution sources: a) brewery effluent (as a low-cost solution) (GS1) and; b) sucrose solution (GS2). GS1 showed 68\%, 60\%, and 99\% higher maximum adsorption constant
\end{abstract}


$\left(\mathrm{q}_{\max }\right)$ for divalent metal ions: iron, copper, and manganese, respectively as compared to raw sand (RS). Coating of $\mathrm{MnO}_{2}$ over the graphitized sand (GSMs: GS1M and GS2M) further helped in Microcystin-LR (MC-LR) removal (3\%-9\%) when inoculated with MC-LR-degraders, but was not as effective in removing metals, organic carbon and nitrogen when compared to just graphitized sand (GS1 or GS2). Inoculating GS and GSMs (for both sugar sources) not only helped in higher MC-LR removal (10\%-15\% more) but also enhanced the removal of other water contaminants including metals, organic nitrogen, and carbon. GS1 showed $20 \%$ and $50 \%$ more MC-LR removal than the sand material when tested at a low and high initial concentration of MC-LR $(5 \mu \mathrm{g} / \mathrm{L}$ and $50 \mu \mathrm{g} / \mathrm{L}$ ). The highest breakthrough period was obtained for GS1 filter using $1 \mathrm{mg} / \mathrm{L}$ Rhodamine-B dye, which was 12 times ( $48 \mathrm{~min}$ ) more than the raw sand filter and almost 2.5 times (second best, $21 \mathrm{~min}$ ) than GS1M. After three cycles of regeneration and reuse of GS1 filter, a decrease of just $14 \%$ in saturation adsorption capacity indicated its high reusability aspects.

Keywords: Manganese-coated sand; Graphene sand; Biofilter; Microcystin; Principal component analysis; Drinking water

\section{Introduction}

The excess presence of various chemical pollutants, nutrients and organic matter in drinking water sources is mainly attributed to the unregulated anthropogenic activities and climate change (Basheer, 2018a, 2018b). This leads to a behavioral change in certain microorganisms which impact their growth and physiological activities. For example, under a high nutrient environment and rise in Carbon dioxide solubility in surface water, cyanobacteria tend to release more cyanotoxins (a secondary metabolite), especially Microcystin-LR: MC-LR (Boopathi and Ki, 2014). Primary pollutants, which are generally present at the macro-scale such as metal ions, natural organic matter (NOMs) and other carbonaceous compounds, are being effectively treated in a drinking water treatment plant (DWTP). However, emerging contaminants, such as cyanotoxins, if not treated, cause acute human exposure to the nerve (neurotoxins) and liver (hepatotoxins) cells at the micro-scale or at very low concentration (as low as $1 \mu \mathrm{g} / \mathrm{L}$ ).

The most prominent cyanotoxin found in the source water is MC-LR (Falconer, 2005). The persistent and stable behavior of MC-LR makes its removal challenging, in terms of high energy requirement and chemical dosage using conventional treatment methods, such as chlorination, ozonation and physical adsorption ( Falconer, 1999; Haider et al., 2003; Ali et al., 2013, 2015a,b, 2016). However, several studies have shown an effective removal of MC-LR or other pollutants using sand filters and other adsorbing materials such as activated carbon and nanoparticles (Bartel et al.and Grützmacher, 2002; Ali et al., 2015a,b; Ho et al., 2006; Drogui et al., 2012; Ali, 2018a, Ali et al., 2018b). Common adsorbents, such as granular activated carbon, powdered activated carbon have been evaluated earlier for the removal of MC-LR (Huang et al., 2007; Keijola et al., 1988; Ho et al., 2011). These adsorbents were effective; however, they incur competitive adsorption due to the presence of NOM in the source water and thus leads to a variation in their dosage making treatment process challenging and complex. Use of agro-industrial waste, such as lentil husk and deinking sludge has been reported to adsorb various pollutants that demonstrates the impact and importance of porosity and 
increase in surface area of the adsorbents (Mo et al., 2018; Kumar et al., 2019). However, the leaching/breakthrough of adsorbed pollutants into the treated water increases the health risk of the consumers. Hence, this work aims to provide an increase in porosity and surface area for a longer period of filter operation.

Due to low operational cost, easy maintenance, and low chemical input, sand filtration is an acceptable treatment approach in DWTPs for natural organic matter (NOMs), metal ions, coliforms, and micro-pollutants. However, complex matrix ingredients present in source water blocks the surface area of the sand particles in a fight for effective and competitive adsorption that leads to a lesser organics and micropollutants removal than expected. This leaves little to no space for the micropollutants, such as MC-LR to get effectively adsorbed on to the sand surface. Thus, modifications in the sand surface can minimize this limitation. Rahman and Praseetha (2016) reported that graphene-coated sand enhanced the metal removal by 10-fold when compared with activated carbon, which they attributed to the enhanced surface property (area and roughness) of the sand particles. Other studies also reported an increase in the removal of organics, dyes, metals, and pollutants by graphene-sand composites (Zularisam et al., 2017; Dubey et al., 2015).

In the past, various forms of metal oxides (iron, manganese) have shown effective functionalization over the sand particles which delivered better removal of metals and organic pollutants as compared to sand (Lai and Chen, 2001; Rachmawati et al., 2013). Also, MC-LR carries a negative charge (pH: 2.1-10.2) in water and is expected to get attracted towards metal oxide surface because of the possible positive charge interface. Thus, modulating the specific surface area (SSA) of sand by graphene coating and functionalization of metal oxide over it was hypothesized to effectively remove MC-LR and other organic pollutants. The use of commercial sugar in the form of sucrose has been tested by some researchers but may prove costly for scale-up operations and hence it can reduce the remarkability of the graphene-sand materials as a powerful, stable and effective adsorbent media (Gupta et al., 2012; Achazhiyath Edathil et al., 2019). Hence, in this study, two different sugar sources were used: a) Brewery effluent (excluding hop) as a low-cost solution and commercial sucrose as a high-cost solution (for comparison), to obtain the graphene-sand composite. For the metal oxide coating, manganese dioxide was functionalized over raw and graphitized sand (obtained from both sugar solution sources).

To further strengthen the hypothesis that inoculating the sand filter (biofilter) may enhance the removal of metal ions, organic carbon or nitrogen and especially emerging contaminants, such as MC-LR reported in few studies (Ho et al., 2006, 2007; Bartel and Grützmacher, 2002; Bourne et al., 2006; Hallé et al., 2015; Zhang et al., 2017), all the prepared sand composites were inoculated with a combination of MC-LR-degrader and native bacterial strains isolated from the filtration unit of a DWTP. The choice of the MC-degrader was strictly based on their biofilm forming-ability. In total, three MC-LR-degraders viz. Arthrobacter ramosus, Bacillus sp. and Sphingomonas sp. were used for the screening process of respective sand composites. This study for the first time reported the preparation of combined manganese oxide-graphene sand composite in general, and the use of low-cost brewery effluent as a sugar source for the synthesis of graphene-sand composite (GSC). To the best of the authors' knowledge, no study has been done earlier for the removal of MC-LR using such sand composites either as physical adsorption or biofilter operation (using graphitized or manganese-impregnated sand). More than 13 WQPs were monitored for over 70 days of biofilter operation in two stages comprising 
physical adsorption and the biological mode to also report for any major variation in a long-term filter operation.

\section{Material and methods}

\subsection{Chemicals and microorganisms}

Microcystin-LR (MC-LR) was purchased from Cayman Chemicals (Ann Arbor, Michigan, MI, USA) and a stock solution of $50 \mathrm{mg} / \mathrm{mL}$ was made by diluting $100 \mu \mathrm{g}$ lyophilized film of MC-LR (as supplied) using $2 \mathrm{~mL}$ of methanol, stored at $-20^{\circ} \mathrm{C}$. Crystal violet and 3-(4,5-dimethylthiazol-2-yl)-2,5-diphenyltetrazolium bromide (MTT) were purchased from Sigma Aldrich, (Ontario, Canada). Various reagents for preparing the stock solution of iron, magnesium and copper (divalent form) including: ferrous ammonium sulphate hexahydrate (iron source), o-phenanthroline, magnesium sulphate (magnesium source), o-cresolphthalein, barium chloride, ethylenediamine tetraacetate, potassium cyanide, and copper sulphate pentahydrate (copper source), were purchased from Sigma Aldrich, (Ontario, Canada). Quartz sand used as the filter media was obtained from Chemin Ste-Foy DWTP, Quebec City, Canada.

MC-degraders: Arthrobacter ramosus (NRRL B-3159), Bacillus sp. (NRRL B-14393) and Sphingomonas sp. (NRRL B-59555) were purchased from NRRL Agricultural Research Service (ARS) culture collection. All the analytical reagents used in preparing nutrient and culture media, LC-MS grade solvents and reagents used to prepare analytical mobile phases, were purchased from Fisher Scientific, (Ontario, Canada).

\subsection{Property of sand grains used for the preparation of different sand composites}

Various sizes of sand grain in the range $125-1000 \mu \mathrm{m}$ were used to formulate an overall filter media with an effective diameter $\left(D_{10}\right)$ of $200 \mu \mathrm{m}$ and coefficient of uniformity of 2.18. Grain size distribution graph and other related details on formulations are presented in the supplementary file (Fig. S1 and Table S1). Hence, for the preparation of GSC and $\mathrm{MnO}_{2}$ coated sand (MOCS) (as discussed in the next section), $200 \mathrm{~g}$ of the formulated sand mixture was used.

\subsection{Preparation of filter media material}

\subsubsection{Preparation of manganese dioxide coated sand (MOCS)}

MOCS was prepared according to the optimized method by Jia et al. (2015) with some modifications. Briefly, $200 \mathrm{~g}$ of formulated sand mixture was soaked overnight in $140 \mathrm{~mL}$ of $9 \%(\mathrm{w} / \mathrm{v}) \mathrm{NaOH}$ solution (base activation increases specific surface area and allows more $\mathrm{MnO}_{2}$ to coat over the sand particles). Afterward, sand was washed and soaked overnight in $7 \%(\mathrm{w} / \mathrm{v}) \mathrm{KMnO}_{4}$ solution and later calcinated at $250^{\circ} \mathrm{C}$ for $4 \mathrm{~h}$. The obtained sand mixture was washed until neutral $\mathrm{pH}$, where excess manganese pellets were removed, and it was finally dried at $120^{\circ} \mathrm{C}$ overnight to obtain MOCS.

\subsubsection{Preparation of sugar (graphene) coated sand or graphene sand composite}

Two different sources of sugar: a) brewery effluent; and b) commercial sucrose, were used to graphitize sand particles. Reducing sugar content of the former was found to be $50 \mathrm{~g} / \mathrm{L}$. Accordingly, around $0.1 \mathrm{~g}$-sugar/gram- 
sand was used as the final optimized recipe for preparing the sugar-sand mixture (for both cases) after several experiments' outcomes in terms of no leaching phenomenon and effective coating as observed from the compound microscope (Supplementary figure: Fig. S2). The leaching was determined using the supernatant of the sand composite prepared after giving it a short spin. The optical density was compared to that of distilled water to understand the clarity of the filtered water. Briefly, $400 \mathrm{~mL}$ (equivalent to $0.1 \mathrm{~g}$-sugar/gram-sand) of brewery effluent was mixed with 200-gram quartz sand in one beaker $(1000 \mathrm{~mL}$ size $)$ and 20 -gram sucrose with 200-gram sand in another beaker. Both mixtures were stirred and heated at $90 \pm 10^{\circ} \mathrm{C}$ to obtain a concentrated sugar-coated sand mixture. Later, the mixture was placed in a crucible. and kept inside the muffle furnace under reduced atmospheric condition and heated to $100^{\circ} \mathrm{C}$ for first $30 \mathrm{~min}$, followed by a gradual increase in temperature until $190^{\circ} \mathrm{C}$ (sugar melting point: $186^{\circ} \mathrm{C}$ ) where it was kept for an hour (to allow the sugar to melt and form a uniform coating). Thereafter, the temperature was ramped to $450^{\circ} \mathrm{C}$ in the next $1 \mathrm{~h}$ and it was maintained for another two hours to ensure complete graphitization of sand. The sample mixture was dried at room temperature and it was later activated using $0.5 \mathrm{M}$ sulphuric acid ( $2 \mathrm{~mL} / \mathrm{gram}$ of GSC) for $30 \mathrm{~min}$. The sand mixture was washed until neutral $\mathrm{pH}$. Finally, the GSC was obtained after an overnight drying at $120^{\circ} \mathrm{C}$.

\subsection{Characterization of the prepared materials}

Scanning electron micrographs (SEM) of the prepared sand composites were recorded using Zeiss Evo ${ }^{\circledR 0}$ Smart SEM system between 5 and $15 \mathrm{kV}$. Fourier-Transform Infrared Spectroscopy (FTIR) of the prepared adsorbents media were recorded using Perkin Elmer, Spectrum RXI, FT-IR instrument fitted with lithium tantalate $\left(\mathrm{LiTaO}_{3}\right)$ detector. Energy dispersive X-ray (EDX) analysis was performed for confirming the atomic and weight percentage of the impregnated elements (manganese, oxygen, silica or carbon) over the sand surface.

\subsection{Metal adsorption studies}

The prepared sand composites were analyzed for their potential in removing the common divalent metal cations that are usually found in the drinking water sources. For the metal adsorption experiment, model columns of $15 \mathrm{~cm}^{3}$ each, were used to place various sand composites. A solution of copper, magnesium, and iron (divalent metal cations) at different initial concentrations of 5, 10, 50, 100, 200, 250, 300 and $350 \mathrm{mg} / \mathrm{L}$ was added to each column. The final equilibrium concentration of copper, magnesium, and iron in the filtered sample was determined spectrophotometrically as detailed by Mehlig (1941), Tesfaldet (2004) and Fortune and Mellon (1938), respectively.

In this study, the adsorption isotherm model which best fitted to the observed values (discussed in detail in Section 3.2) was Langmuir isotherm. This model assumes monolayer adsorption onto a surface that contains a finite number of adsorption sites assuming no transmigration of the adsorbate in the plane surface (Hameed et al., 2007). The isotherm is represented by Eq. (1) as follows:

$$
\frac{C e}{q e}=\frac{1}{b q \max }+\frac{C e}{q \max }
$$


The linear plot of (Ce/qe) vs qe (as represented by Eq. (1)) obeyed Langmuir model where constants b and $\mathrm{q}_{\max }$ signifies the energy of adsorption and the maximum adsorption capacity, respectively, obtained from the intercept and slope.

The essential characteristics of the parameter obtained from the Langmuir adsorption isotherm can be used to predict the sorbate-sorbent affinity using a dimensionless constant, $\mathrm{R}_{\mathrm{L}}$ (separation factor). This is expressed by the following Eq. (2):

$$
\mathrm{R}_{\mathrm{L}}=\frac{1}{1+b C i}
$$

where, $\mathrm{Ci}$ is the initial sorbate concentration. The shape of the isotherm and nature of the adsorption is indicated by the range of $\mathrm{R}_{\mathrm{L}}$ values presented as under:

$\mathrm{R}_{\mathrm{L}}>1$, Unfavorable; $\mathrm{R}_{\mathrm{L}}=1$ Linear; $0<\mathrm{R}_{\mathrm{L}}<1$, Favorable; $\mathrm{R}_{\mathrm{L}}=0$, Irreversible.

\subsection{Biofilm forming ability of different microcystin-degraders over various sand composites}

Biofilm formation in a biosand filter is a prerequisite. Three different MC-degraders in form of Arthrobacter ramosus (A), Bacillus sp. (B) and Sphingomonas sp. (S) (Manage et al., 2009; Hu et al., 2012, Alamri, 2012; Somdee et al., 2013) were co-cultured with the native bacterial community that were isolated from the biofilm sample of the filtration unit in a DWTP (Chemin Ste-Foy, Quebec City, Canada). The dominant bacterial strains present in the collected biofilm sample were identified as Pseudomonas fragi and Chryseobacterium sp. (combinedly represented as X from hereon) in our previous study (Kumar et al., 2018). These strains were also found to be potent in degrading MC-LR. In another study done in parallel (data not shown), the coculturing of MC-degraders with these native bacterial strains were found to enhance their potential in degrading MC-LR. Hence, in the current study, the co-culture model was adopted for the screening process. In a real scenario, it would be more rational to choose the co-culture mode too $(\mathrm{A}+\mathrm{X}, \mathrm{B}+\mathrm{X}$, and $\mathrm{S}+\mathrm{X})$ for the screening process. Fig. S3 shows the schematic representation of the unique set-up prepared for this objective. Two sets for each sand composite (fixed particle size: $300 \mu \mathrm{m}, 10 \mathrm{~g}$ ) were placed horizontally in a model column. The columns were operated by the auto-dosage pumps.

Luria-Bertani was used as the culture media to grow the bacterial cells which were centrifuged and rinsed thrice to obtain the bacterial pellets. Thereafter (determining their count $/ \mathrm{mL}$ ), it was suspended in the nutrient buffer to prepare the inoculum source for the filter media. After every $6 \mathrm{~h}, 20 \mathrm{~mL}\left(6 \times 10^{7}\right.$ cells $\left./ \mathrm{mL}\right)$ of inoculum source $(\mathrm{A}+\mathrm{X}, \mathrm{B}+\mathrm{X}$, and $\mathrm{S}+\mathrm{X}$, separately) were pumped to all the six sand composites allowing enough time for the bacteria to proliferate and form the biofilm. The process was continued for 10 days and after 2-day, 4-day, 7-day, and 10-day, sand composites from top layer was taken partially ( $\sim 0.1 \mathrm{~g}$ for all cases). This sample was suspended in $1.5 \mathrm{~mL}$ of tap water in a microcentrifuge tube and vortexed to detach the biofilm formed over the sand composite particles. The supernatant consisting of biomass and live cells were seeded in 
96-well microplates in triplicates to quantify the biofilm using crystal violet (CV) assay and MTT assay. CV assay and MTT assay were performed to quantify the biomass and live cells present in the biofilm, respectively. The protocol for the same is mentioned in our previous study (Kumar et al., 2019). Negative control comprised the sand composite materials passed using tap water (not the nutrient-biocell solution) and positive control comprised Staphylococcus epidermidis which is known as a good biofilm former (Chusri et al., 2012). The result obtained from the positive control was used to compare the biofilm quantification (for both cell viability as well as cell biomass) of other bacteria.

\subsection{Optimization of the input parameters using central composite design}

For optimizing the physical parameters of the Lake water, used as an influent matrix in the sand composite columns, three input parameters with different levels were chosen: (a) pH (3-levels, 6, 7, and 8); (b) initial turbidity (3-levels, 10 NTU (Nephelometric Turbidity Units), 20 NTU, and 30 NTU); and (c) retention time (4levels, 1-h, 2-h, 3-h, and 4-h). Hence, a total of 36 input combinations were tested for each sand composite. The optimization test before commencing the filter operation was considered as an important aspect as it brought out the working strengths and limitations of the initial parameters. The output of the responses was recorded in terms of total coliform removed, total turbidity removed, $\mathrm{pH}$ change, dissolved oxygen content, conductivity, total organic carbon (TOC) removal, flow rate, and ammonia removal. The model column used for the optimization step was of internal diameter $22 \mathrm{~mm}$ and a total height of $650 \mathrm{~mm}$ ( $490 \mathrm{~mm}$ for the media, $120 \mathrm{~mm}$ for the headspace, $40 \mathrm{~mm}$ for drainage). All the responses obtained were analyzed using DesignExpert 7.0 software by central composite experimental design and critical solutions were obtained through response surface methodology. The desirability index was reported for all six sand composites and found to be in the range of $0.3-0.4$.

\subsection{Column experiment and setup details}

Similar column dimensions were used for the main filter operation too as discussed in the previous section. Fig. 1 shows the schematic diagram of biofilter under operation. The filter operation was conducted in three stages: stage (a) No bacterial inoculation stage (for six cycles: 1 cycle equivalent to 7 days); stage (b) biofilm formation stage, and stage (c) post-biofilm operation (for additional six cycles). 


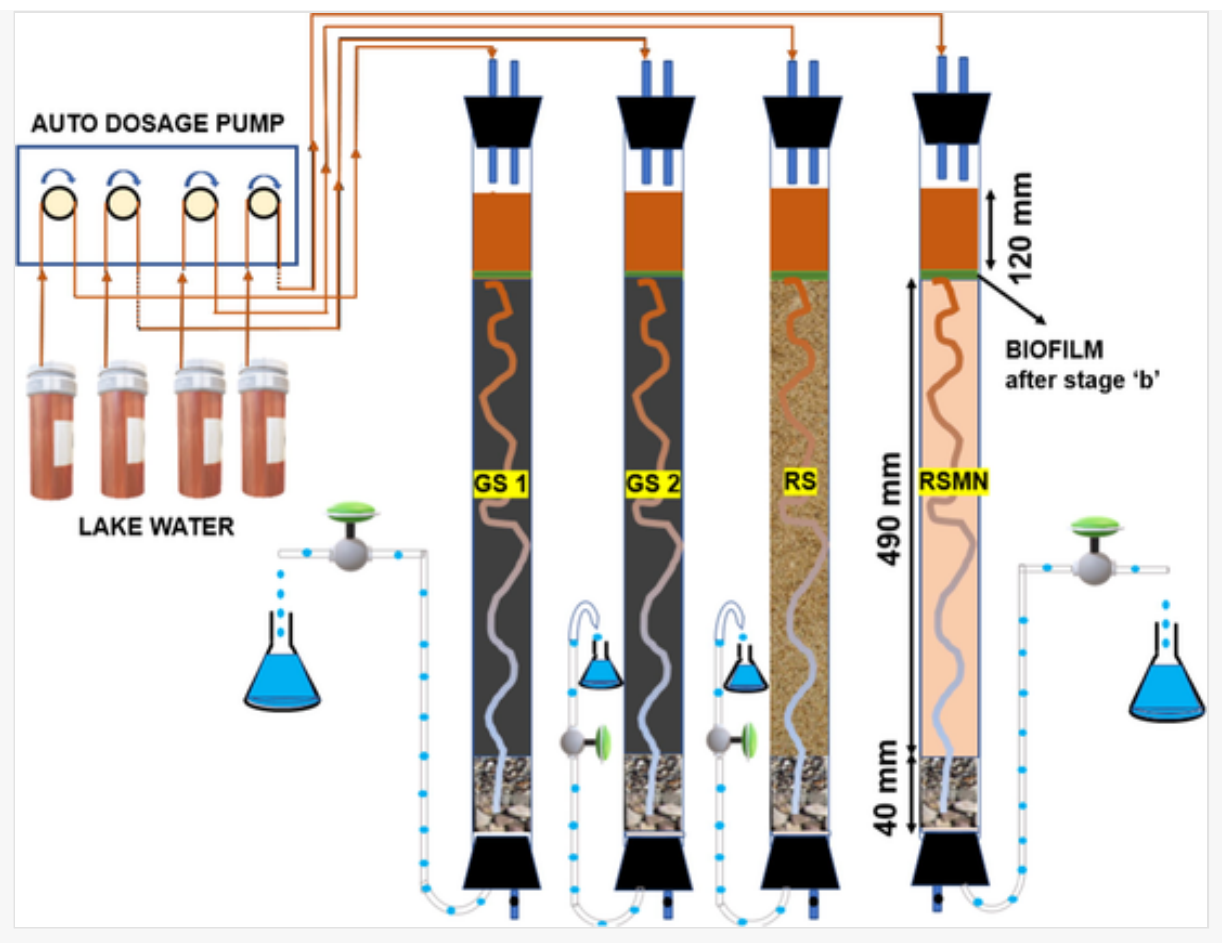

Schematic representation of the filter operation (other filters: GS1MN and GS2MN are not shown here).

Stage operations 'a' and 'c' were carried out for every sand composite filters to distinguish the physical and biological degradation performance for various water quality parameters (WQPs). The respective screened-coculture bacterial strains as obtained from the screening process (Section 2.6) were inoculated $\left(6 \times 10^{8}\right.$ cells $/ \mathrm{mL}$ ) for each sand composite filter. After every $6 \mathrm{~h}$, the inoculum was passed through the filter column using an auto-dosage pump and was continued for ten days. A decrease in the flow rate, increased protein concentration and cell viability of the formed biofilm, along with an enhanced TOC removal indicated the successful biofilm formation over the sand composites (not shown here). Later, the filter columns were run for additional six cycles (stage 'c') to evaluate various water quality parameters viz, total coliform removal, total turbidity removal, dissolved oxygen, metal removal, flow rate, conductivity, $\mathrm{pH}$, TOC removal and ammonia removal.

\subsection{Analysis of water quality parameters (WQPs)}

\subsubsection{Coliform removal, turbidity removal, DOC removal, and ammonia removal}

Total coliform removal was determined twice a cycle (every 3rd and 6th day of a 7-day cycle) in the filtered water sample by membrane filtration technique according to the standard method APHA (1998). Total coliform was reported in $\mathrm{CFU} / 100 \mathrm{~mL}$ and removal percentage was determined based on the initial coliform content present in the lake water. The average count of the total initial coliform was found to be $1581 \pm 342 \mathrm{CFU} / 100 \mathrm{~mL}$ (average from 9 plates count).

The initial turbidity of the lake water was $6 \pm 0.9 \mathrm{NTU}$, which was less than the maximum limit value as obtained from the optimized conditions for each sand composite. Hence, to operate the filters under the worst exposure, very fine hydrated clay particles $(<25 \mu \mathrm{m}$ soaked overnight) was used to mimic and increase the 
turbidity of the influent water. The final turbidity of the filtered sample was observed every day using HACH instrument 2100 model and it was reported in NTU. DOC of the effluent sample was determined using a

Shimadzu 5000A analyzer (Shimadzu, Japan). In brief, around $30 \mathrm{~mL}$ of the filtered sample was filtered using a $0.45 \mu \mathrm{m}$ glass-fibre filter. Initial DOC of the influent water (Lake water) was observed to be $9 \pm 1.7 \mathrm{mg} / \mathrm{L}$.

Ammonia-N, nitrite-N, and nitrate-N were determined in the filter sample as per the method described by Naghdikumar et al. (20197). Initial ammonia-N, nitrite-N and nitrate-N concentration in the lake water was determined to be $1.3 \mathrm{mg} / \mathrm{L}, 2.1 \mathrm{mg} / \mathrm{L}$, and $0.5 \mathrm{mg} / \mathrm{L}$, respectively and was made up to corresponding $5 \mathrm{mg} / \mathrm{L}$, $10 \mathrm{mg} / \mathrm{L}$ and $50 \mathrm{mg} / \mathrm{L}$ using the stock solution: ammonium sulfate (source of ammonia), sodium nitrite (for nitrite) and sodium nitrate (for nitrate).

\subsection{2 pH, dissolved oxygen, metals removal, conductivity}

$\mathrm{pH}$ and $\mathrm{DO}$ measurement of the filtered water provided the information about bacterial activity within the column. DO was measured using a portable F4-Standard probe (Mettler Toledo Inc). A working solution of metals in the form of magnesium, copper, and iron were prepared in lake water matrix at an initial concentration of $20 \mathrm{mg} / \mathrm{L}$ for both stages ('a' and 'c'). The method to determine the metal ions is discussed in Section 2.5. The conductivity of the filtered sample was measured using Mettler Toledo ${ }^{\mathrm{TM}}$ S230 SevenCompact ${ }^{\mathrm{TM}}$ Conductivity Meter.

\subsubsection{Flow rate and MC-LR removal studies of filter columns}

The flow rate was reported in $\mathrm{m} / \mathrm{h}\left(\mathrm{m}^{3} / \mathrm{m}^{2} / \mathrm{h}\right)$ for each filter after the end of each cycle. During the flow rate measurement, stagnant water head was maintained at around $80 \mathrm{~mm}$ measured from the top layer of sand composite media.

Backwashing was performed for each filter (during stage 'c' filter operation) because of a continuous decrease in the flow rate due to the biomass formed inside the column filter. The flow rate at no point should decrease to 1/4th the initial flow rate at which the column was designed. This was just considered as the subjective minimum throughout the experiment.

The appropriate volume of MC-LR from stock solution was spiked in the lake water (matrix) to obtain an initial MC-LR concentration of $50 \mu \mathrm{g} / \mathrm{L}$. For the MC-LR analysis, the filtered sample from each sand composite column was collected and the samples were processed using a method adapted from Fayad et al. (2015). Briefly, a $20-\mu \mathrm{L}$ sample aliquot was analyzed by ultra-high-performance liquid chromatography coupled to a Thermo Q-Extractive Orbitrap mass spectrometer through a positive electrospray ionization source. MC-LR was detected in full-scan MS mode (resolution set at 70,000 FWHM at $200 \mathrm{~m} / \mathrm{z}$ ) and quantified against a matrix-matched lake water calibration curve. The method limit of quantification (LOQ) was set at the lowest concentration level of the calibration curve (i.e. $0.1 \mu \mathrm{g} / \mathrm{L}$ ). Also, after the end of stage 'c' operation, all the filters were passed with three different MC-LR concentration: $5 \mu \mathrm{g} / \mathrm{L}$ (low), $20 \mu \mathrm{g} / \mathrm{L}$ (medium) and $40 \mu \mathrm{g} / \mathrm{L}$ (high), to better understand the limitation of the biofilters.

\subsection{Regeneration and reuse studies}


Regeneration and reusability of the column is an important aspect to understand the behavior of the adsorbent filter media and overall economic feasibility of the column. For this, Rhodamine-B solution was used as the model dye-adsorbate (initial concentration, Co: $1 \mathrm{mg} / \mathrm{L}$ ) for each adsorbent (various sand composites). A continuous flow rate of $4 \mathrm{~mL} /$ minute was chosen for a material bed depth of $7.5 \mathrm{~cm}$ (Supplementary Figure: Fig. S4). After each throughput volume of $40 \mathrm{~mL}, \mathrm{OD}_{550}$ was determined (using a 96-well plate) in triplicates to quantify the amount of Rhodamine-B adsorbed on to the material. After the exhaustion of the bed material $(\mathrm{C} / \mathrm{Co} \sim 1)$, the adsorbents were regenerated via acetone solution and reused for a total of three cycles to understand the reusability potential of the adsorbent. The saturated adsorption capacity (Wsat: $\mathrm{mg} / \mathrm{g}$ ) of each material was calculated using Eq. (3):

$$
\text { Wsat }=\left(\int_{0}^{t} U o C o\left(1-\frac{c}{c_{0}}\right)\right) /(\mathrm{g}-\text { adsorbent }
$$

where, Uo is the flow velocity in L/minute, Co is the initial adsorbate concentration in $\mathrm{mg} / \mathrm{L}$ and $\mathrm{t}$ is the breakthrough time in minutes.

\subsection{Statistical analysis and graphics}

All statistical analyses comprising standard deviation, average, student $t$-test, $\mathrm{p}$-value comparison, Principal Component Analysis (PCA) and all graphical presentations were performed in ORIGIN software (Version 8.5; OriginLab).

\section{Results and discussion}

\subsection{Characterization of sand composites}

\subsubsection{FT-IR}

Fig. 2(A) shows the absorbance spectra for RS, GS1 and GS2 and Fig. 2(B) shows the absorbance spectra for RS, GS1M, and GS2M. The only absorbance peak for RS at $560 \mathrm{~cm}^{-1}$ indicated $\mathrm{Si}-\mathrm{O}-\mathrm{Si}$ bond while spectra for GS1 and GS2 showed additional and characteristic graphene absorbance peak at $1050 \mathrm{~cm}^{-1}, 1125 \mathrm{~cm}^{-1}$, and $1610 \mathrm{~cm}^{-1}$ attributing to $\mathrm{C}-\mathrm{O}$ bond, $\mathrm{C}-\mathrm{O}-\mathrm{C}$ linkage, and $\mathrm{C}=\mathrm{C}$ bond, respectively. This ensured complete graphitization of sugar onto the sand particles (Dubey et al., 2015). The $\mathrm{C}-\mathrm{O}-\mathrm{C}$ linkage in sucrose (GS2) is a glycosidic bond other mono sugars (glucose or fructose). 

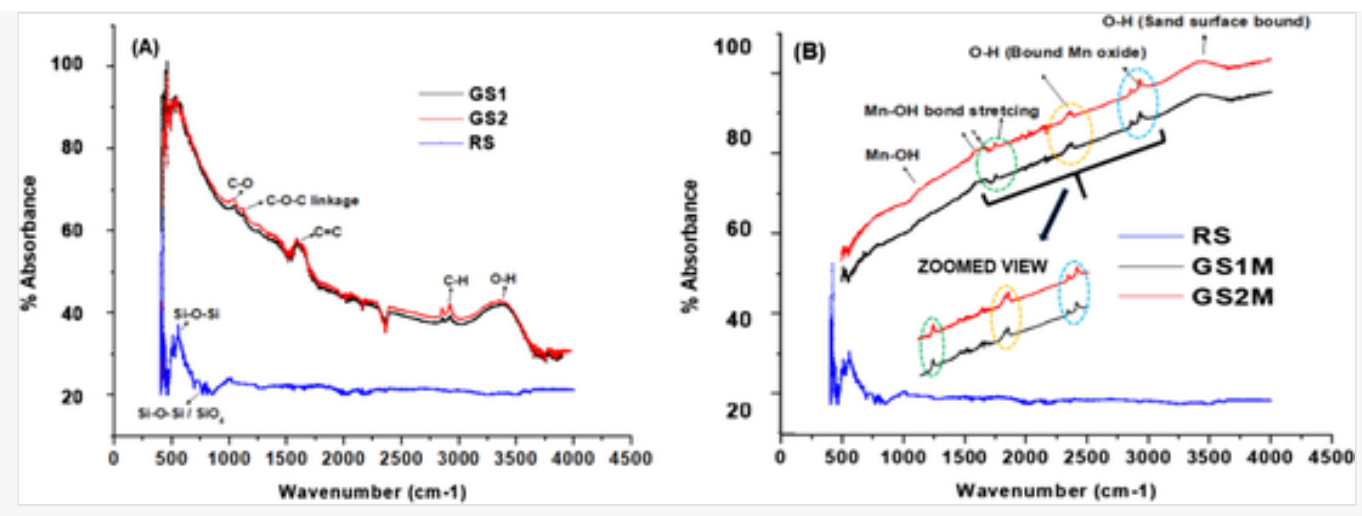

Fourier-transform infrared spectroscopy spectra for the sand composites: (A) raw sand: graphitized sand 1 and graphitized sand 2 and; (B) manganese impregnated graphitized sand 1 and 2.

Fig. 2(B) showed the absorbance FTIR-spectra for the manganese coated graphitized-sand composites (GS1M and GS2M). Absorbance peaks around wavenumber $1125 \mathrm{~cm}^{-1}, 1750 \mathrm{~cm}^{-1}, 2360 \mathrm{~cm}^{-1}, 2750 \mathrm{~cm}^{-1}$ and $3300 \mathrm{~cm}^{-1}-3700 \mathrm{~cm}^{-1}$ were observed. The peak at $1125 \mathrm{~cm}^{-1}$ can be attributed to the $\mathrm{Mn}-\mathrm{OH}$ functionalization group that might have generated due to the base treatment step that was performed before the calcination step, indicating activation of surface area (Chaudhry et al., 2016). The absorption peak at $1750 \mathrm{~cm}^{-1}$ in case of GS1M and GS2M indicated vibrational stretch of $\mathrm{Mn}-\mathrm{OH}$ bond that may be due to the link between manganese atom and the graphitized carbon atoms. The peak at $2360 \mathrm{~cm}^{-1}$ might indicate $-\mathrm{OH}$ bound manganese oxide, while the peak at $2750 \mathrm{~cm}^{-1}$ and $3300-3700 \mathrm{~cm}^{-1}$ indicates $-\mathrm{OH}$ bond functionalized at the sand surface.

\subsubsection{EDX}

The elemental composition of the coated sand composites was further confirmed by EDX (quantitively). Table 1 shows the elemental composition in terms of atomic \% and weight \% for all the sand composites. Uncoated sand (RS) showed a ratio of 1:4 for silica atoms (20\%) and oxygen atoms (80\%) which indicated a general $\mathrm{SiO}_{4}$ structure (tetrahedron) of the quartz sand. GS1 and GS2, both showed $<1 \%$ atomic composition of silica as also observed by Zularisam et al. (2017), while $>70 \% />20 \%$ and $>55 \% />40 \%$ carbon/oxygen atoms for GS1 and GS2, respectively. This further ensured complete graphitization of sugar onto the sand surface. More manganese dioxide compounds were coated over GS2 (17\%) as compared to GS1 (7\%). This might be due to the morphological differences occurred due to graphitization of pure sugar (sucrose) in case of GS2 as compared to brewery sugar in case of GS1. Herein, the sugar media (brewery effluent) consisted of a mix of many sugars including xylose and galactose (GS1) that may have changed the property of the final graphitized surface thereby allowing attachment of fewer manganese dioxides.

Table 1

(i) The presentation of Tables and the formatting of text in the online proof do not match the final output, though the data is the same. To preview the actual presentation, view the Proof. 
EDX analysis of all the sand composites in terms of weight and atomic $\%$.

\begin{tabular}{|c|c|c|c|c|c|c|c|c|c|c|c|c|}
\hline & RS & & RSMN & & GS1 & & GS2 & & GS1M & & GS2M & \\
\hline Element & W (\%) & A (\%) & W (\%) & A (\%) & W (\%) & A (\%) & W (\%) & A (\%) & W (\%) & A (\%) & W (\%) & A (\%) \\
\hline $\mathbf{O}$ & 68.2 & 78.7 & 45.7 & 70.1 & 31.0 & 26.2 & 33.8 & 40.4 & 22.1 & 22.6 & 30.1 & 39.4 \\
\hline Si & 30.8 & 20.2 & 13.3 & 10.6 & 0.9 & 0.4 & 11.5 & 0.3 & 0.2 & 0.2 & 0.8 & 0.6 \\
\hline Mn & 0 & 0 & 40.9 & 18.2 & 0 & 0 & 0 & 0 & 23.8 & 6.8 & 44.4 & 16.9 \\
\hline C & 0 & 0 & 0 & 0 & 64.1 & 71.9 & 54.6 & 58.3 & 52.4 & 70.2 & 23.6 & 41.9 \\
\hline Others & 1 & 1 & 0.01 & 1 & 3.9 & 1.4 & 0.1 & 0.9 & 0.8 & 0.2 & 1 & 1 \\
\hline
\end{tabular}

W: Weight; A: Atomic.

\subsubsection{SEM}

Fig. 3 shows the SEM image of the prepared sand composites. As can be observed from the zoomed figure for RSMN, GS1, GS2, GS1M, and GS2M, coating of manganese/carbon graphitized layer was successfully obtained. From the SEM images of GS1 and GS2 particle, the graphitized coating showed a diffused porous morphology as compared to the manganese-coated graphitized sand (GS1M or GS2M) where latter showed more of a planar morphology. This can be the reason for relatively higher adsorption of metal ions (all three of them) by the graphitized sand (GS1 and GS2) as compared to the manganese coated graphitized sand (GS1M and GS2M) (discussed more in detail in Section 3.2). 


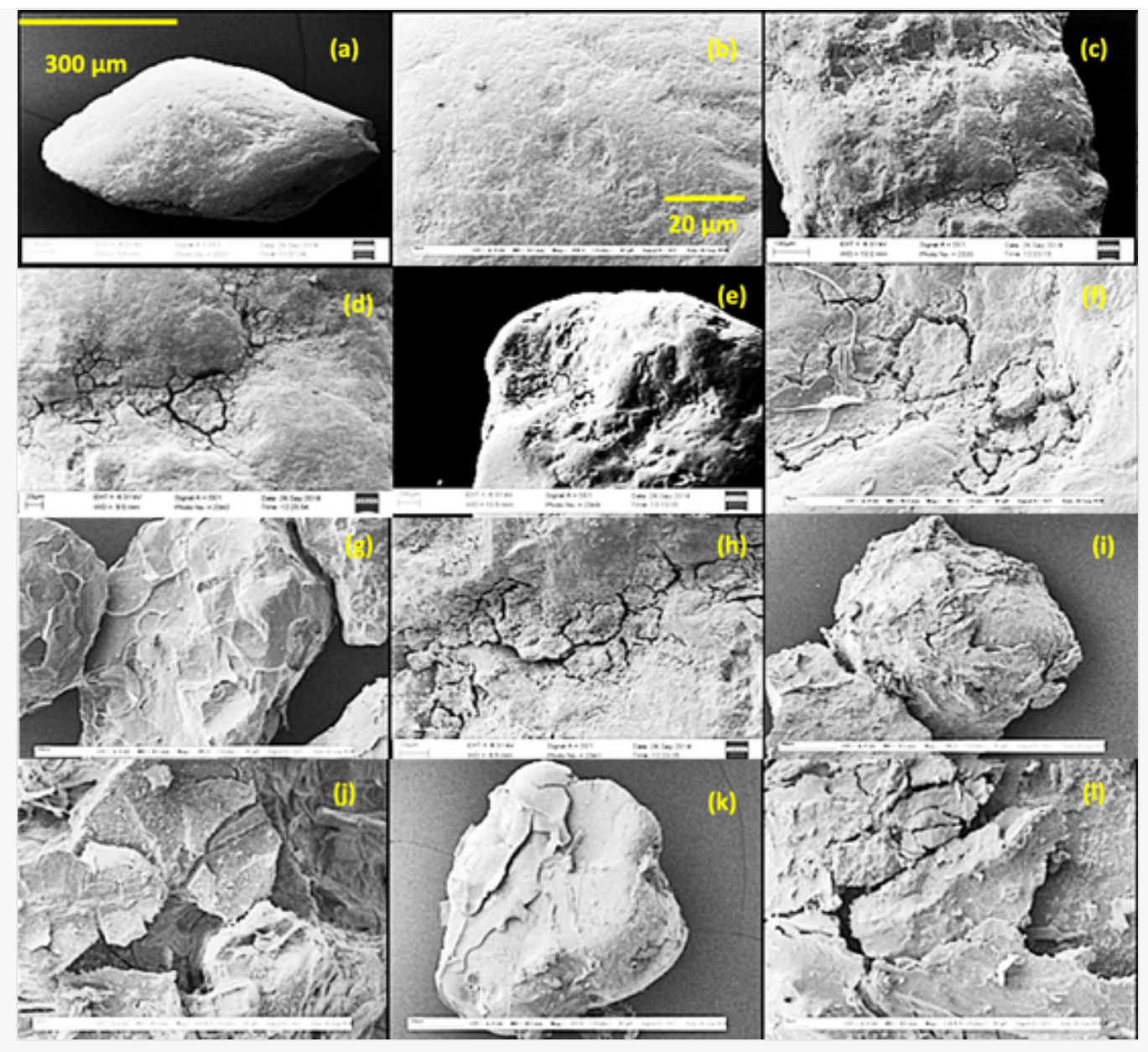

SEM image of all sand composite [RS (a \& b); RSMN (c \& d); GS2 (e \& f); GS1 (g \& h); GS1M (i \& j); GS2M (k \& l) Figure b, $\mathrm{d}, \mathrm{f}, \mathrm{h}, \mathrm{j}$ and $\mathrm{l}$ are the zoomed-in view of a, c, e, g, i and $\mathrm{k}$ and scale is shown as a reference by Fig. 3 (a and b for full and zoomed view, respectively)] (RS: Raw sand; RSMN: Raw sand manganese; GS1: Brewery solution sugar-coated sand; GS2: Sucrose solution coated sand; GS1M and GS2M: Manganese dioxide-coated graphitized sand from respective sugar sources.

\subsection{Metal adsorption studies}

For all the three divalent metal ions tested, the observed equilibrium points $\left(\mathrm{C}_{\mathrm{e}} \mathrm{vs}_{\mathrm{e}} / \mathrm{q}_{\mathrm{e}}\right)$ fit the Langmuir isotherm model as represented by Eq. (1). The linearity of the curve revealed the applicability of these isotherms for the adsorption. Fig. 4(A), (B) and (C) represents the Langmuir isotherm of iron, copper, and magnesium for all the six sand composites. 

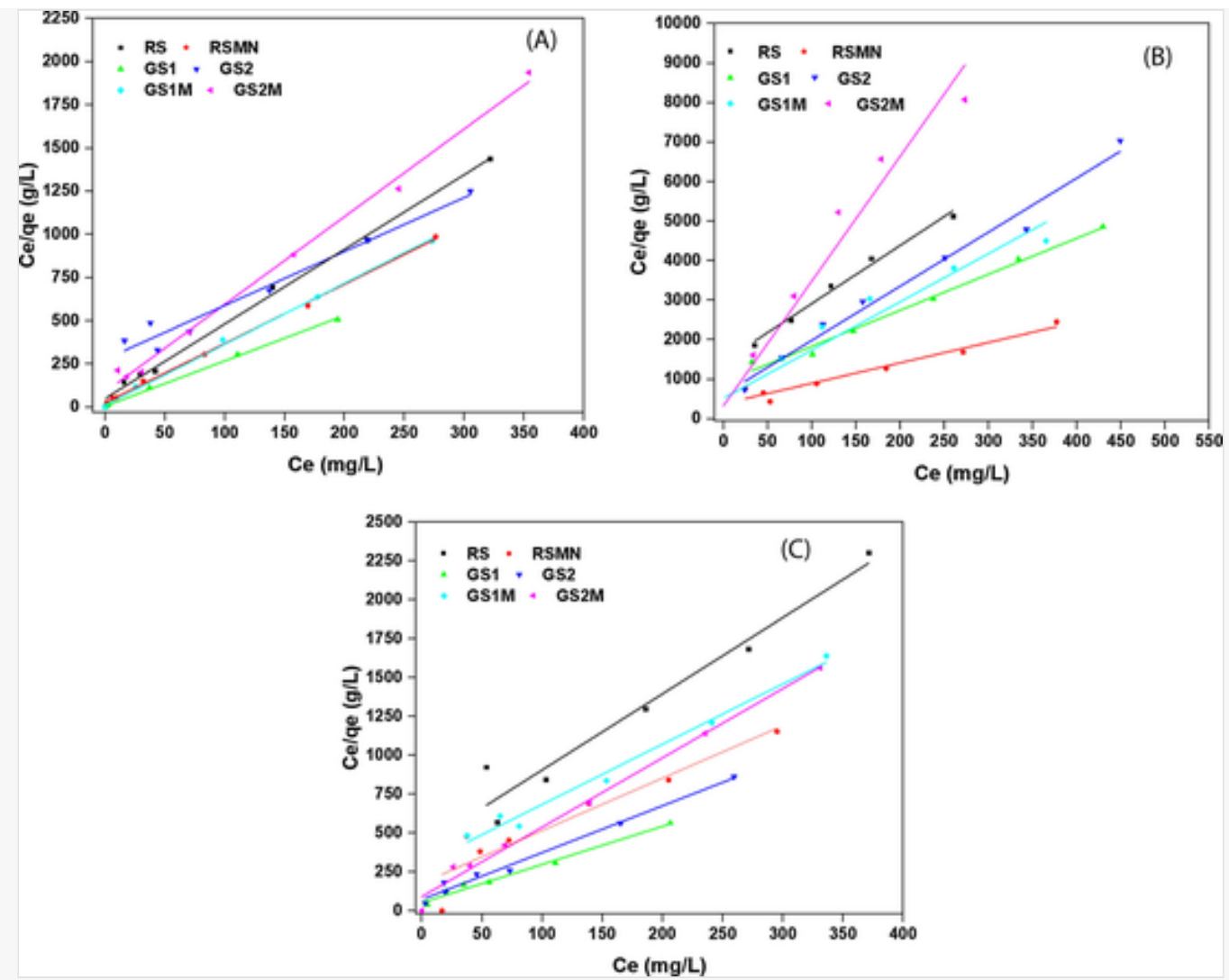

Linear Langmuir isotherm adsorption curve for all the sand composites for the adsorption of (a) iron; (b) copper and; (c) magnesium. (RS: Raw sand; RSMN: Raw sand manganese; GS1: Brewery solution sugar-coated sand; GS2: Sucrose solution coated sand; GS1M and GS2M: Manganese dioxide-coated graphitized sand from respective sugar sources).

Table 2 presents the estimated isotherm parameters for all the sand composites. $\mathrm{R}_{\mathrm{L}}$ value indicated the favorable nature of the adsorption for all the three metal ions onto the sand composites (Table 2). From the $\mathrm{q}_{\max }$ values, it can be inferred that iron (range: $0.195 \mathrm{mg} / \mathrm{g}-0.380 \mathrm{mg} / \mathrm{g}$ ) and manganese (range: $0.204 \mathrm{mg} / \mathrm{g}-$ $0.408 \mathrm{mg} / \mathrm{g}$ ) are more adsorbed on sand composites (all six adsorbent material studied) as compared to the copper ions (range: $0.031 \mathrm{mg} / \mathrm{g}-0.193 \mathrm{mg} / \mathrm{g}$ ). Highest adsorption capacity $\left(\mathrm{q}_{\max }\right)$ for iron, copper, and manganese was shown by GS1, RSMN, and GS1, respectively. RS performed the worst in terms of adsorption capacity for all the three divalent metal ions (Table 2). In general, $\mathrm{MnO}_{2}$ coating over the graphitized sand (GS1M or GS2M) did not really enhance the metal adsorption capacity (as compared to GS1 or GS2) while $\mathrm{MnO}_{2}$ coating onto the raw sand (RSMN) has helped in enhancing the sorption capacity of raw sand (Table 2). Also, RSMN mostly performed at par with the graphitized sand (GS1 or GS2) in terms of maximum adsorption capacity $\left(\mathrm{q}_{\max }\right)$ for all the three divalent metal ions indicating graphitization may not be necessary to remove more metal ions.

Table 2

(i) The presentation of Tables and the formatting of text in the online proof do not match the final output, though the data is the same. To preview the actual presentation, view the Proof. 
Metal adsorption parameters obtained from the Langmuir adsorption curve $\left(\mathrm{C}_{\mathrm{e}} \mathrm{vs}_{\mathrm{e}} / \mathrm{q}_{\mathrm{e}} \mathrm{plot}\right)$.

\begin{tabular}{|c|c|c|c|c|c|c|c|}
\hline Metal Ions & $\begin{array}{l}\text { Estimated isotherm } \\
\text { parameters }\end{array}$ & RS & RSMN & GS1 & GS2 & GS1M & GS2M \\
\hline \multirow{4}{*}{ Iron $\left(\mathrm{Fe}^{2+}\right)$} & $\mathrm{q}_{\max }(\mathrm{mg} / \mathrm{g})$ & 0.226 & 0.286 & 0.380 & 0.268 & 0.281 & 0.195 \\
\hline & $\mathrm{b}(\mathrm{L} / \mathrm{mg})$ & 0.162 & 0.133 & 0.466 & 0.013 & 0.300 & 0.058 \\
\hline & $\mathrm{R}^{2}$ & 0.996 & 0.998 & 0.998 & 0.966 & 0.997 & 0.994 \\
\hline & $\mathrm{R}_{\mathrm{L}}$ range & $0.10-0.55$ & $0.10-0.60$ & $0.10-0.30$ & $0.13-0.94$ & $0.10-0.40$ & $0.10-0.76$ \\
\hline \multirow{4}{*}{ Copper $\left(\mathrm{Cu}^{2+}\right)$} & $\mathrm{q}_{\max }(\mathrm{mg} / \mathrm{g})$ & 0.068 & 0.193 & 0.109 & 0.068 & 0.073 & 0.031 \\
\hline & $\mathrm{b}(\mathrm{L} / \mathrm{mg})$ & 0.042 & 0.013 & 0.009 & 0.010 & 0.022 & 0.094 \\
\hline & $\mathrm{R}^{2}$ & 0.957 & 0.950 & 0.990 & 0.990 & 0.982 & 0.969 \\
\hline & $\mathrm{R}_{\mathrm{L}}$ range & $0.05-0.83$ & $0.13-0.94$ & $0.18-0.96$ & $0.16-0.95$ & $0.08-0.90$ & $0.02-0.68$ \\
\hline \multirow{4}{*}{$\begin{array}{l}\text { Magnesium } \\
\left(\mathrm{Mg}^{2+}\right)\end{array}$} & $\mathrm{q}_{\max }(\mathrm{mg} / \mathrm{g})$ & 0.204 & 0.363 & 0.408 & 0.332 & 0.257 & 0.224 \\
\hline & $\mathrm{b}(\mathrm{L} / \mathrm{mg})$ & 0.011 & 0.008 & 0.047 & 0.041 & 0.013 & 0.048 \\
\hline & $\mathrm{R}^{2}$ & 0.951 & 0.968 & 0.987 & 0.987 & 0.985 & 0.991 \\
\hline & $\mathrm{R}_{\mathrm{L}}$ range & $0.15-0.947$ & $0.20-0.96$ & $0.04-0.81$ & $0.05-0.82$ & $0.08-0.94$ & $0.04-0.81$ \\
\hline
\end{tabular}

RS: Raw sand; RSMN: Raw sand manganese; GS1: Brewery solution sugar-coated sand; GS2: Sucrose solution coated sand; GS1M and GS2M: Manganese dioxide-coated graphitized sand from respective sugar sources.

\subsection{Biofilm forming ability}

As discussed in Section 2.6, three MC-degraders A, B, and S were co-cultured with $\mathrm{X}(\mathrm{A}+\mathrm{X}, \mathrm{B}+\mathrm{X}$, and $\mathrm{S}+\mathrm{X})$ and distributed equally in terms of cell concentration $\left(6 \times 10^{8}\right.$ cells $\left./ \mathrm{mL}\right)$. This combination of bacterial coculture was passed through the sand composites to quantify the formed biofilm. Fig. S5 shows the schematic representation of the setup (supplementary file). Fig. 5(A) and (B) shows the MTT and CV assay absorbance values for four different day sampling: 2nd day, 4th day, 7th day and 10th day. It can be observed that the biomass (CV) and cell viability (MTT) showed a positive correlation (for every sand composites) which means more cell viability, more is the cell biomass and vice-versa. A general trend of increasing absorbance values can be observed for both the assays as time progressed. In almost every sand composite, the MTT assay (Fig. 5 (A)) showed a decrease in cell viability after 7 days which indicated that the bacterial cell activity remained intact for 7 days before they died due to nutrient limitation or other reasons. 


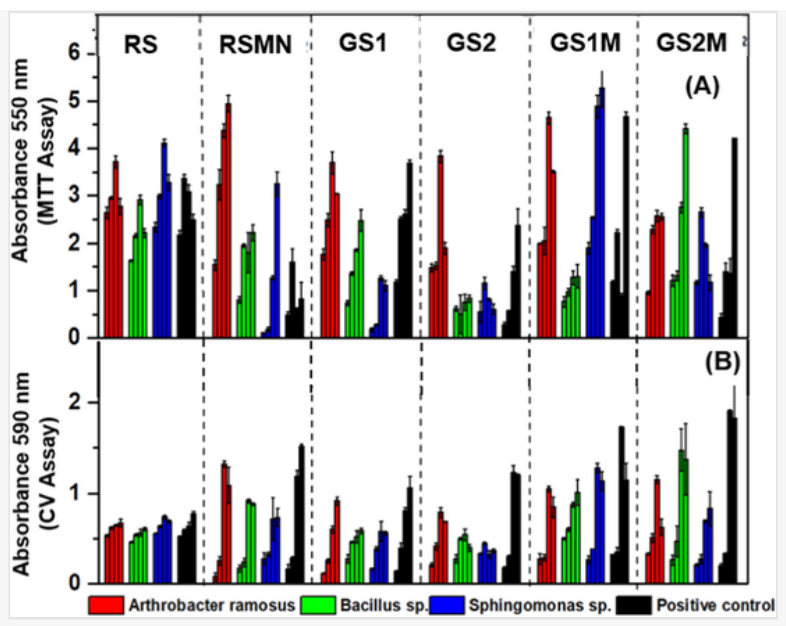

Absorbance bar chart for the quantification of biofilm in terms of: (a) biomass (CV assay); and (b) cell viability (MTT assay) (RS: Raw sand; RSMN: Raw sand manganese; GS1: Brewery solution sugar-coated sand; GS2: Sucrose solution coated sand; GS1M and GS2M: Manganese dioxide-coated graphitized sand from respective sugar sources).

Based on the highest absorbance values achieved for MTT as well as CV assay, the MC-degrader- co-culture screened for RS, RSMN, GS1, GS2, GS1M, GS2M were S+X, A+X, A+X, A+X, S+X, and B+X, respectively (Fig. 5). Statistically, for RS, both A and S performed well in comparison to the positive control (PC). However, lower p-value for pair $\{S+X\}:\{P C\}(0.75)$ as compared to pair $\{A+X\}:\{P C\}(0.93)$, made $\mathrm{S}+\mathrm{X}$ the better choice in terms of the statistical significance. For RSMN, GS1, and GS2, A+X showed better biomass and cell viability quantification, while it was B $+\mathrm{X}$ which performed well for GS2M. For GS1M, both $\mathrm{A}+\mathrm{X}$ and $\mathrm{S}+\mathrm{X}$ performed equally well in comparison to the $\mathrm{PC}$ and thus once again based on the $\mathrm{p}$-value between pair: $\{\mathrm{A}+\mathrm{X}\}:\{\mathrm{PC}\}(0.83)$ and $\{\mathrm{S}+\mathrm{X}\}:\{\mathrm{PC}\}(0.48), \mathrm{S}+\mathrm{X}$ was preferred over $\mathrm{A}+\mathrm{X}$.

\subsection{Optimization of the input parameters}

For every sand composite, the optimized results as obtained through the CCD analysis using RSM were decoded (from the experimental code values) of each input parameter studied. Table 4 presents the optimized value of variables and other operational characteristics used during the optimization experiment. Except for GS2M, other sand composites showed desirable output at $\mathrm{pH} 7.3$ as compared to 7.13 for the former. Whilst, optimum turbidity was found in between 13 and 15 NTU for all the sand composites, the residence time was found to be around $20 \mathrm{~min}$ for all the sand composite except GS2M (over $18 \mathrm{~min}$ ). This meant, if residence time at any stage of the filter operation exceeded 20 min and turbidity $>15 \mathrm{NTU}$, it might show a decline in its performance. The filters are operated under no-forced flow condition (free fall under steady water head level). The time to filter $40 \mathrm{~mL}$ of standing water (TFSW) for all the filters were less than 20 min for the stage 'a' operation (no biofilm condition). However, under biofilm conditions (stage 'c'), the TFSW increased for all the sand composite filters. Hence, it was ensured that the flow rate was put back to around same initial linear flow velocity through backwashing operation as it was during the start of stage 'c' operation (for the filters crossing TSFW of $20 \mathrm{~min}$ ). The influent water was fortified with hydrated-clay particles to achieve initial turbidity of not more than the optimized value (between 13 and $15 \mathrm{NTU}$ ) whereas the $\mathrm{pH}$ was ensured to be in the optimized range (7.13-7.30). 
(i) The presentation of Tables and the formatting of text in the online proof do not match the final output, though the data is the same. To preview the actual presentation, view the Proof.

Operational characteristics of the sand composite filters.

\begin{tabular}{|c|c|c|c|c|c|c|c|c|c|}
\hline \multirow[t]{2}{*}{ Filter } & \multirow{2}{*}{$\begin{array}{l}\text { Density } \\
\left(\mathrm{kg} / \mathrm{m}^{3}\right)\end{array}$} & \multirow{2}{*}{$\begin{array}{l}\text { Pore } \\
\text { volume } \\
(\mathrm{mL})\end{array}$} & \multirow{2}{*}{$\begin{array}{l}\text { Surface } \\
\text { area } \\
\left(\mathrm{cm}^{2} / \mathrm{g}\right)\end{array}$} & \multicolumn{3}{|c|}{$\begin{array}{l}\text { Optimized conditions (Input } \\
\text { parameters) }\end{array}$} & \multirow{2}{*}{$\begin{array}{l}\text { Screened MC- } \\
\text { LR- degrader } \\
\text { Stage 'c' }\end{array}$} & \multicolumn{2}{|c|}{$\begin{array}{l}\text { Time to filter } 40 \mathrm{~mL} \\
\text { standing water } \\
\text { (minutes) }\end{array}$} \\
\hline & & & & pH & $\begin{array}{l}\text { Turbidity } \\
\text { (NTU) }\end{array}$ & $\begin{array}{l}\text { Residence } \\
\text { time (min) }\end{array}$ & & Stage 'a' & Stage 'c' \\
\hline RS & 2.50 & 44.7 & 80 & 7.3 & 13.1 & 20 & $\begin{array}{l}\text { Sphingmonas } \\
\text { sp. }\end{array}$ & $3.4 \pm 0.6$ & $8.3 \pm 1.9$ \\
\hline RSMN & 2.45 & 42.8 & 82 & 7.3 & 13.35 & 20 & $\begin{array}{l}\text { Arthrobacter } \\
\text { ramosus }\end{array}$ & $4.4 \pm 0.7$ & $9.7 \pm 1.4$ \\
\hline GS1 & 2.17 & 46.2 & 93 & 7.3 & 15 & 20 & $\begin{array}{l}\text { Arthrobacter } \\
\text { ramosus }\end{array}$ & $5.1 \pm 0.6$ & $14.7 \pm 1.5$ \\
\hline GS2 & 2.26 & 48.1 & 88 & 7.3 & 14.85 & 20 & $\begin{array}{l}\text { Arthrobacter } \\
\text { ramosus }\end{array}$ & $5.7 \pm 1.2$ & $17.6 \pm 2.9$ \\
\hline GS1M & 2.12 & 45.7 & 94 & 7.3 & 15 & 20 & $\begin{array}{l}\text { Sphingmonas } \\
\text { sp. }\end{array}$ & $6.6 \pm 0.8$ & $20.6 \pm 2.6$ \\
\hline GS2M & 2.13 & 44.3 & 93 & 7.13 & 15.1 & 18.8 & Bacillus sp. & $7.3 \pm 1.3$ & $20.3 \pm 3.1$ \\
\hline
\end{tabular}

(RS: Raw sand; RSMN: Raw sand manganese; GS1: Brewery solution sugar-coated sand; GS2: Sucrose solution coated sand; GS1M and GS2M: Manganese dioxide-coated graphitized sand from respective sugar sources).

\section{Table 4}

(i) The presentation of Tables and the formatting of text in the online proof do not match the final output, though the data is the same. To preview the actual presentation, view the Proof.

Water Quality Parameters (WQPs) for all the sand composites during filter operation for both stages ('a' and 'c').

\begin{tabular}{|c|c|c|c|c|c|c|c|}
\hline Water quality parameter & Stage & RS & RSMN & GS1 & GS2 & GS1M & GS2M \\
\hline \multirow{2}{*}{ Conductivity } & $\begin{array}{l}\text { Stage } \\
\text { a }\end{array}$ & $208 \pm 8$ & $186 \pm 11$ & $192 \pm 8$ & $180 \pm 13$ & $206 \pm 17$ & $219 \pm 18$ \\
\hline & $\begin{array}{l}\text { Stage } \\
\mathrm{c}\end{array}$ & $223 \pm 6$ & $214 \pm 7$ & $215 \pm 4$ & $218 \pm 15$ & $217 \pm 7$ & $238 \pm 10$ \\
\hline
\end{tabular}




\begin{tabular}{|c|c|c|c|c|c|c|c|}
\hline \multirow[t]{2}{*}{ DO (mg/L) } & $\begin{array}{l}\text { Stage } \\
\text { a }\end{array}$ & $4.8 \pm 0.3$ & $4.6 \pm 0.4$ & $4.5 \pm 0.2$ & $3.1 \pm 0.2$ & $2.9 \pm 0.3$ & $2.9 \pm 0.3$ \\
\hline & $\begin{array}{l}\text { Stage } \\
\mathrm{c}\end{array}$ & $3.9 \pm 0.1$ & $3.7 \pm 0.2$ & $3.5 \pm 0.2$ & $2.82 \pm 0.2$ & $2.8 \pm 0.3$ & $2.6 \pm 0.2$ \\
\hline \multirow{2}{*}{$\begin{array}{l}\text { Time to filter } 40 \mathrm{~mL} \text { standing } \\
\text { water (min) }\end{array}$} & $\begin{array}{l}\text { Stage } \\
\text { a }\end{array}$ & $3.4 \pm 0.6$ & $4.4 \pm 0.7$ & $5.1 \pm 0.6$ & $5.7 \pm 1.2$ & $6.6 \pm 0.8$ & $7.3 \pm 1.3$ \\
\hline & $\begin{array}{l}\text { Stage } \\
\mathrm{c}\end{array}$ & $8.3 \pm 1.9$ & $9.7 \pm 1.4$ & $14.7 \pm 1.5$ & $17.6 \pm 2.9$ & $20.6 \pm 2.6$ & $20.3 \pm 3.1$ \\
\hline \multirow{2}{*}{$\mathrm{NH}_{3}-\mathrm{N}(\mathrm{mg} / \mathrm{L})$} & $\begin{array}{l}\text { Stage } \\
\text { a }\end{array}$ & $6.86 \pm 0.58$ & $6.83 \pm 0.65$ & $6.14 \pm 0.64$ & $6.29 \pm 0.11$ & $6.25 \pm 0.19$ & $6.42 \pm 0.54$ \\
\hline & $\begin{array}{l}\text { Stage } \\
\mathrm{c}\end{array}$ & $6.43 \pm 0.32$ & $6.37 \pm 0.43$ & $4.01 \pm 0.48$ & $5.02 \pm 0.23$ & $4.21 \pm 0.21$ & $4.45 \pm 0.29$ \\
\hline \multirow{2}{*}{$\mathrm{NO}_{2}{ }^{-}-\mathrm{N}(\mathrm{mg} / \mathrm{L})$} & $\begin{array}{l}\text { Stage } \\
\text { a }\end{array}$ & $6.9 \pm 0.3$ & $5.6 \pm 0.3$ & $4.6 \pm 0.3$ & $6.3 \pm 0.3$ & $4.5 \pm 0.3$ & $4.9 \pm 0.2$ \\
\hline & $\begin{array}{l}\text { Stage } \\
\mathrm{c}\end{array}$ & $6.4 \pm 0.2$ & $5 \pm 0.18$ & $4.5 \pm 0.4$ & $5.4 \pm 0.5$ & $4.7 \pm 0.4$ & $4.4 \pm 0.6$ \\
\hline \multirow{2}{*}{$\mathrm{NO}_{3}{ }^{-}-\mathrm{N}(\mathrm{mg} / \mathrm{L})$} & $\begin{array}{l}\text { Stage } \\
\text { a }\end{array}$ & $20.7 \pm 0.7$ & $17.9 \pm 0.5$ & $7.7 \pm 0.9$ & $14.3 \pm 1.7$ & $8.9 \pm 1.6$ & $11.3 \pm 0.3$ \\
\hline & $\begin{array}{l}\text { Stage } \\
\mathrm{c}\end{array}$ & $22.2 \pm 0.7$ & $15.1 \pm 0.9$ & $6.7 \pm 0.1$ & $8.5 \pm 0.9$ & $8.2 \pm 0.7$ & $7.7 \pm 1.6$ \\
\hline \multirow{2}{*}{ pH } & $\begin{array}{l}\text { Stage } \\
\mathrm{a}\end{array}$ & $6.8 \pm 0.1$ & $6.6 \pm 0.1$ & $6.6 \pm 0.1$ & $6.4 \pm 0.1$ & $6.4 \pm 0.1$ & $6.4 \pm 0.2$ \\
\hline & $\begin{array}{l}\text { Stage } \\
\mathrm{c}\end{array}$ & $6.7 \pm 0.1$ & $6.6 \pm 0.2$ & $6.5 \pm 0.1$ & $6.5 \pm 0.1$ & $6.4 \pm 0.1$ & $6.5 \pm 0.1$ \\
\hline \multirow{2}{*}{ Total coliform (per $100 \mathrm{~mL}$ ) } & $\begin{array}{l}\text { Stage } \\
\text { a }\end{array}$ & $31.2 \pm 4.4$ & $23.5 \pm 5.1$ & $10.8 \pm 1.7$ & $11.3 \pm 3.2$ & $10.2 \pm 2.9$ & $10 \pm 3.8$ \\
\hline & $\begin{array}{l}\text { Stage } \\
\mathrm{c}\end{array}$ & $24.1 \pm 6.7$ & $19.6 \pm 5.4$ & $10.2 \pm 3.3$ & $9 \pm 3.1$ & $8 \pm 3.3$ & $8.3 \pm 5.7$ \\
\hline \multirow{2}{*}{ Turbidity (NTU) } & $\begin{array}{l}\text { Stage } \\
\text { a }\end{array}$ & $2.6 \pm 0.8$ & $1.5 \pm 0.4$ & $0.8 \pm 0.2$ & $0.8 \pm 0.3$ & $0.9 \pm 0.3$ & $0.9 \pm 0.4$ \\
\hline & $\begin{array}{l}\text { Stage } \\
\mathrm{c}\end{array}$ & $2.2 \pm 0.9$ & $1.3 \pm 0.6$ & $0.8 \pm 0.2$ & $0.9 \pm 0.4$ & $0.9 \pm 0.3$ & $1.4 \pm 0.3$ \\
\hline \multirow{2}{*}{$\operatorname{Mg}(\mathrm{mg} / \mathrm{L})$} & $\begin{array}{l}\text { Stage } \\
\text { a }\end{array}$ & $9 \pm 0.3$ & $4.2 \pm 0.04$ & $3.4 \pm 0.4$ & $5 \pm 0.4$ & $9 \pm 0.3$ & $12.2 \pm 0.2$ \\
\hline & $\begin{array}{l}\text { Stage } \\
\mathrm{c}\end{array}$ & $10.8 \pm 0.5$ & $4.1 \pm 0.2$ & $2.4 \pm 0.15$ & $4.4 \pm 0.5$ & $7.3 \pm 0.8$ & $10 \pm 1.1$ \\
\hline $\mathrm{Cu}(\mathrm{mg} / \mathrm{L})$ & Stage & $14.8 \pm 1.8$ & $10.1 \pm 1.6$ & $13.9 \pm 0.5$ & $14.3 \pm 1.2$ & $13.9 \pm 2.1$ & $15.6 \pm 1.7$ \\
\hline
\end{tabular}




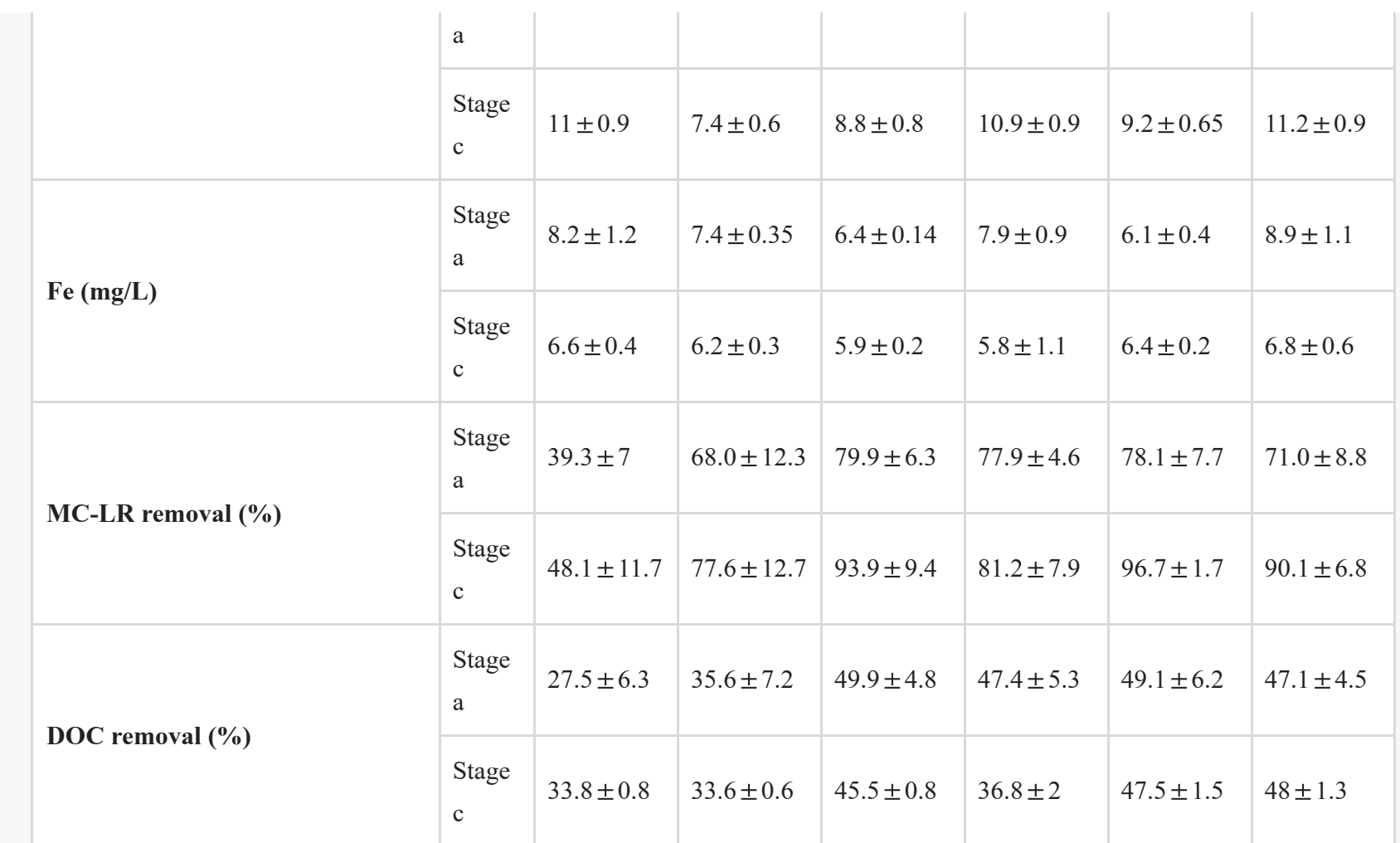

Initial $\mathrm{NH}_{3}-\mathrm{N}, \mathrm{NO}_{2}{ }^{-}-\mathrm{N}, \mathrm{NO}_{3}{ }^{-}-\mathrm{N}$, Iron, Copper and Magnesium, MC-LR and TOC concentration were: $10 \mathrm{mg} / \mathrm{L}, 10 \mathrm{mg} / \mathrm{L}$, $50 \mathrm{mg} / \mathrm{L}, 20 \mathrm{mg} / \mathrm{L}, 20 \mathrm{mg} / \mathrm{L}, 20 \mathrm{mg} / \mathrm{L}, 60 \mathrm{mg} / \mathrm{L}$ and $9 \mathrm{mg} / \mathrm{L}(\mathrm{TOC}=26.5 \mathrm{mg} / \mathrm{L}$ and DOC $9 \mathrm{mg} / \mathrm{L}$ ), respectively. (RS: Raw sand; RSMN: Raw sand manganese; GS1: Brewery solution sugar-coated sand; GS2: Sucrose solution coated sand; GS1M and GS2M: Manganese dioxide-coated graphitized sand from respective sugar sources).

\subsection{Water contaminants (WCs) removal}

Table 5 presents the overall result of the WCs for both the stages: 'a' and 'c'. It can be observed that ammonia, nitrite and nitrate removal increased during stage 'c' operation for all the filters attributing the capability of the MC-LR-degraders in each filter to nitrify ammonia. Highest ammonia $(60 \%)$, nitrite $(55 \%)$ and nitrate $(86 \%)$ removal were observed in filter GS1. In general, graphitization of sugar enhanced the ammonia $(25 \%$ \& $15 \%$ for GS1 and GS2), nitrite (19\% \& $8 \%$ for GS1 and GS2) and nitrate (30\% \& 26\% for GS1 and GS2) removal capacity as compared to the raw sand material (RS) while coating of $\mathrm{MnO}_{2}$ over graphitized sand (GS1M and GS2M) failed to further enhance the potential of graphitized sand (GS1 or GS2) in removing ammonia, nitrate, and nitrate. Enhanced removal potential by graphitized sand filters may be attributed to the biological conversion of ammonia, denitrification process, and effective cell-synthesis as described by Healy et al. (2007) due to an increase in cell biomass of the screened MC-LR-degraders in conjugation with X. Also, an increase in the surface area of the graphitized sand (Table 3) allowed effective nitrification which got further elevated because of the active biofilm growth (stage 'c' compared to stage 'a') (Davidson et al., 2008).

\section{Table 5}

(i) The presentation of Tables and the formatting of text in the online proof do not match the final output, though the data is the same. To preview the actual presentation, view the Proof. 
Breakthrough curve parameters for all the sand composite material for 3 cycles of reuse.

\begin{tabular}{|c|c|c|c|c|c|c|c|c|c|}
\hline \multirow{2}{*}{ Filter } & \multicolumn{3}{|c|}{$\begin{array}{l}\text { Breakthrough time at } \mathrm{C} / \mathrm{Co}=0.05 \text { (in } \\
\text { minutes) }\end{array}$} & \multicolumn{3}{|c|}{$\begin{array}{l}\text { Throughput volume at breakthrough } \\
(\mathrm{mL})\end{array}$} & \multicolumn{3}{|c|}{ Wsat (mg/g) } \\
\hline & Cycle 1 & Cycle 2 & Cycle 3 & Cycle 1 & Cycle 2 & Cycle 3 & $\begin{array}{l}\text { Cycle } \\
1\end{array}$ & $\begin{array}{l}\text { Cycle } \\
2\end{array}$ & $\begin{array}{l}\text { Cycle } \\
3\end{array}$ \\
\hline RS & 3.6 & 3.4 & 2.8 & 37 & 32 & 31 & 1.41 & 1.25 & 1.11 \\
\hline RSMN & 4.1 & 3.8 & 3.4 & 43 & 39 & 36 & 1.7 & 1.54 & 1.44 \\
\hline GS1 & 50 & 44 & 40 & 504 & 454 & 412 & 18.61 & 17.54 & 15.89 \\
\hline GS2 & 4.7 & 4.2 & 3.9 & 49 & 43 & 44 & 4.5 & 4.2 & 2.74 \\
\hline GS1M & 21 & 14 & 9 & 219 & 145 & 98 & 8.49 & 8.11 & 7.44 \\
\hline GS2M & 5 & 4.6 & 4.2 & 58 & 51 & 46 & 3.65 & 3.47 & 2.72 \\
\hline
\end{tabular}

-----RS: Raw sand; RSMN: Raw sand manganese; GS1: Brewery solution sugar coated sand; GS2: Sucrose solution coated sand; GS1M and GS2M: Manganese impregnated graphitized sand from respective sugar sources.

Both coliform and turbidity removal for graphitized filters (GS1, GS2, GS1M, and GS2M) were found to be $10 \%-15 \%$ more than the RS filter. This might be due to an increased surface area of the graphitized sand ( Table 3) that led to the availability of more attachment sites and hence allowed an effective entrapment of the coliforms between the sand composites (Jenkins et al., 2011). Also, coliform removal was observed to be $15 \%$ $-20 \%$ more during the stage ' $c$ ' operation as compared to stage 'a' operation. This might be due to the predation mechanism by the active MC-LR-degraders co-cultured with $\mathrm{X}$ acting as protists (Unger and Collins, 2008). GS2 and GS2M showed a slight turbid effluent during stage 'c' operation (cycle 7 - cycle 12) that indicated quick maturation of the attached biomass that led to its detachment carrying away the mimicked clay particles along with it.

Highest iron (70\%) and magnesium (89\%) removal were observed for GS1 filter, while copper removal was maximally removed by RSMN filter (63\%). On an average, magnesium, copper and iron removal for all the filters were further enhanced during the stage 'c' operation as compared to stage 'a' operation by around 5\% $-10 \%, 20 \%-30 \%$ and $10 \%-15 \%$, respectively. Increased removal of metal ions (by up to $20 \%$ ) in RSMN filter as compared to the manganese dioxide-coated graphitized sand composite filter (GS1M or GS2M) may be explained due to the fact that a significant amount of free surface was occupied by the manganese dioxide particles along with the cage-like $\mathrm{C}-\mathrm{O}-\mathrm{C}$ bond structure (as shown in Fig. S6) thereby allowing less attachment of the metal ions. Out of all the four graphitized sand composites (GS1, GS2, GS1M or GS2M), only GS1 showed better or comparable metal removal to RSMN filter. This can further be explained because of the availability of more free sites for the metal ions (iron, copper or magnesium) to attack the oxygen atom (negatively charged) as compared to GS1M and GS2M where the oxygen atom is already attached to the manganese atoms (Fig. S6). However, the reason GS1 performed better in the removal of metal ions as compared to GS2 may be attributed to a more porous and rough structure of the former as can be seen from the SEM images: Fig. 3) which allowed better metal ion pore diffusion and hence more attachment before exhaustion or equilibrium is reached (Bajpai et al., 2017). 


\subsection{Removal of Microcystin-LR}

An average of 10\%-15\% increase in MC-LR removal under stage 'c' operation was observed for all the filters (except GS2, only 4-5\% increase) indicating that the screened-MC-LR-degrader contributed to the MC-LR removal. Their activity and increase in the biomass concentration were evident from the fact that $\mathrm{pH} / \mathrm{DO}$ decrease further during stage ' $c$ ' operation (Table 4) and TSFW significantly increased (2-3-fold due to increasing biomass) for all the filters. As compared to RS filter, RSMN, GS1, GS2, GS1M, and GS2M showed an enhancement of $29.5 \%, 45.8 \%, 33.1 \%, 48.6 \%$, and $42 \%$, respectively for the removal of MC-LR. It may be possible that other MC-LR-degraders that was not selected after the screening process (as discussed in detail in Section 3.3) could have performed better. However, the screening was done based on an important prerequisite of the bacterial strains that are required for the successful operation of any biofilters, i.e. cell viability and cell biomass (Section 3.3). It was very interesting to observe that during stage 'a' filter operation, GS1 performed the best in terms of MC-LR removal (close to 80\%) among all the filters and filter GS1M and GS2M underperformed (despite having 3\%-6\% more surface area, Table 3) or were at par with the former.

In general, graphitized sand showed enhanced MC-LR removal as compared to the RS in both the stages ( Table 4). However, manganese coating over the graphitized sand has not really helped in further removal of MC-LR (stage 'a' result accounting 2\%-7\% decrease in value). Thus, in stage 'c' operation, an increase of 3\% and 9\% in MC-LR removal for GS1M as compared to GS1M and GS2 as compared to GS2M, respectively, indicate the prominent contribution of biodegradation. In the last four cycles (cycle 8-12), filter GS1 and GS1M during stage ' $c$ ' operation showed complete removal of MC-LR (data in the supplementary file, Table S2) indicating that the brewery effluent used as the low-cost sugar solution performed better than the commercial sugar (sucrose). The surface composition, roughness and other morphological details of GS1 were key factors responsible for the MC-LR removal, and not the manganese dioxide impregnation factor.

Fig. 6 shows the residual MC-LR concentration for all the biofilters when tested at three different initial MCLR levels after stage 'c' operation was finished. GS1 continued to perform well and showed $<1 \mu \mathrm{g} / \mathrm{L}$ of residual MC-LR concentration at low MC-LR levels (5 and $20 \mu \mathrm{g} / \mathrm{L}$ ) while the MC-LR concentration just exceeded $(\sim 1.8 \mu \mathrm{g} / \mathrm{L})$ the critical limit as set by the WHO $(1 \mu \mathrm{g} / \mathrm{L})$. Among other biofilters, the residual MCLR concentration was found to be in order: GS1MN $<$ GS2MN $<$ RSMN $<$ GS $2<$ RS. 


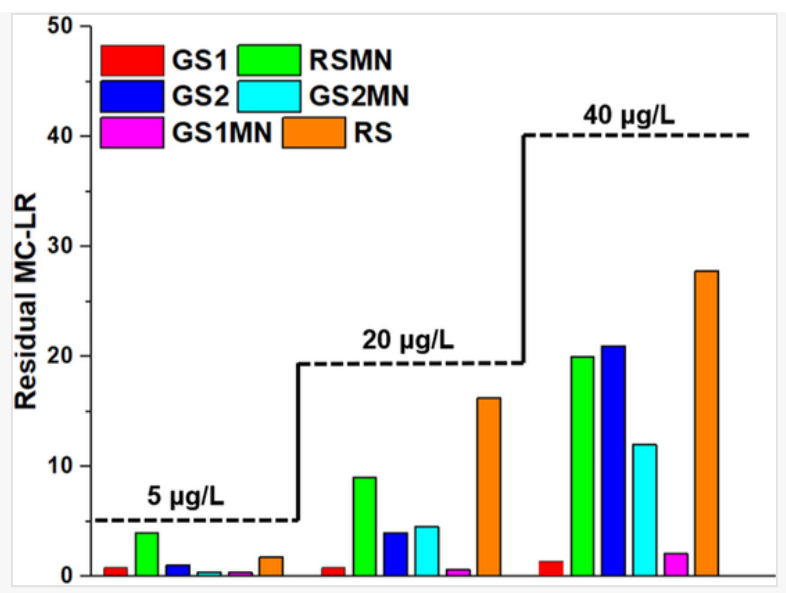

Residual MC-LR concentration tested for all the sand composites in a column study for three different initial MC-LR concentration: $5 \mu \mathrm{g} / \mathrm{L}, 20 \mu \mathrm{g} / \mathrm{L}$ and $40 \mu \mathrm{g} / \mathrm{L}$.

\subsection{Interpretation of the WCs removal using PCA analysis}

Fig. 7 shows the PCA biplot graph for the observation variables in the form of filters used and Water Quality Parameters (WQPs) as the variables. Based on the cluster of variables around the principal components (PC1 and PC2), WQPs can be mainly divided into two groups: (a) metals ion removal (WQP1) and; (b) organic carbon and nitrogen, MC-LR and coliform/turbidity removal (WQP2). For the stage 'a' filter operation, PC1, and PC2 accounted for $61 \%$ and $25 \%$ of the total variation in data, respectively, for a total of $86 \%$ (Fig. 7(A)). Metal removal variables are closely aligned with PC2 while other variables are closely aligned with PC1. This indicated a strong correlation among the WQP1 and WQP2 variables (correlation matrix is shown in the supplementary file, Table S3). Both RS and RSMN showed less correlation towards the WQPs (WQP1 or WQP2) except copper removal (as is also evident from results, Table 4). Filter GS1, GS1M, and GS2M are on the right side of the biplot graph, where GS1 and GS1M are closely spaced with the WQP2 variables indicating a positive correlation with each other and hence also signifies better filter potential resulting in a high removal of WQP1 and WQP2 variables. The clustering of WQP2 variables was mostly orthogonal to copper removal variable indicating no correlation with each other.

\section{Fig. 7}



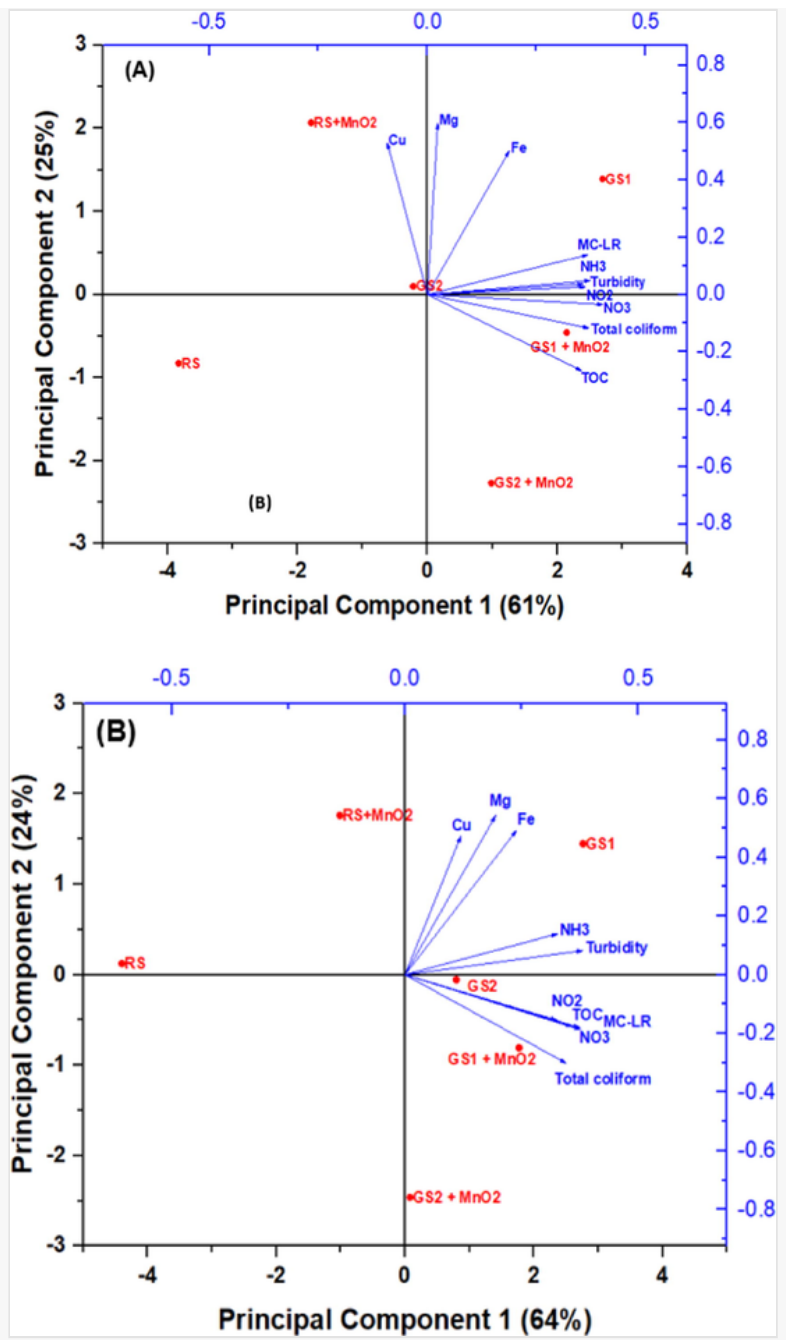

Principal component analysis (PCA) for the WQPs obtained under filter operation for stage (A) stage 'a' and; (B) stage 'b' RS: Raw sand; RSMN: Raw sand manganese; GS1: Brewery solution sugar-coated sand; GS2: Sucrose solution coated sand; GS1M and GS2M: Manganese impregnated graphitized sand from respective sugar sources.

On the other hand, PCA biplot for the stage 'c' operation (Fig. 7(B)) accounted for $64 \%$ and $24 \%$ for PC1 and PC2, respectively, for a total of $88 \%$ variation in data (Fig. 7(B)). Akin to stage 'a' operation, the WQP1 are clustered together around PC2 (though less as compared to stage 'a' PCA biplot) while WQP2 are clustered around PC1. Also, RS and RSMN were once again present on the left side of the biplot graph indicating weak correlation for the WQPs (WQP1 or WQP2) removal as is also evident from their results (Table 4). The observation variable (filters) on the same side of the WQPs represented a high correlation between each other (correlation matrix in the supplementary section). For stage 'c' PCA biplot, WQP1 and WQP2 variables are on the same side (right) of the observation variables: GS1, GS2, GS1M, and GS2M. Among WQP1 variables, Cu, $\mathrm{Mg}$, and Fe showed high correlation (Table S3) with each other while, among WQP2 variables, TOC, MC-LR, $\mathrm{NO}_{2}{ }^{-}$and $\mathrm{NO}_{3}{ }^{-}$showed a very strong correlation with each other (Fig. 7(B). Higher correlation (correlation coefficient: 0.90 ) between TOC removal and MC-LR removal is generally found seldom because of the competition between the organic carbon compound and MC-LR as the primary choice of substrate for the bacterial cells. This can be framed as a very positive research inference as most of the time the high competition is reported in other studies (Dixit et al., 2018). However, under stage 'a' operation, the competition 
was observed between TOC removal and MC-LR removal, as they were poorly correlated with each other (correlation coefficient: 0.67 ).

In short, the sand composite filters (especially, RS and RSMN) were found to face a tough challenge when metal ions were present in the source water as is evident from the PC2 loading of more than $24 \%$ for both stages of filter operation. GS2 and GS2M (especially GS2M) were quite far from PC1 loading as compared to GS1 and GS1M observation variables indicating the effectiveness of brewery sugar-coated sand in the removal of WQPs. For instance, GS2 was found to be just on the left side of the PCA biplot under stage 'a' operation and GS2M occupied a much lower or farther position from the PC1 axis. In contrary, GS1 is nicely positioned with WQP1 and WQP2 and is less orthogonal to the variable vectors. WQP1 under stage 'c' operation was found to be more oriented towards the PC1 axis and hence less orthogonal and closer to the WQP2 variables indicating the importance of biofilm (or biodegradation) in removing the metal ions (as for the removal of WQP2 it enhanced quite substantially, refer to Table 4).

\subsection{Regeneration and reuse of filter media}

Fig. 8(A, B and C) shows the breakthrough curves of each sand composites for three cycles (two cycles of regeneration). Table 5 shows the breakthrough curve parameters for all the sand composite filters. The breakthrough time $(\mathrm{C} / \mathrm{Co}=0.05)$ for $\mathrm{RS}, \mathrm{RSMN}, \mathrm{GS} 1, \mathrm{GS} 2, \mathrm{GS} 1 \mathrm{M}$, and $\mathrm{GS} 2 \mathrm{M}$ was found to be around $3.67 \mathrm{~min}, 4.1 \mathrm{~min}, 50 \mathrm{~min}, 4.67 \mathrm{~min}, 21 \mathrm{~min}$, and $5 \mathrm{~min}$, respectively.

\section{Fig. 8}
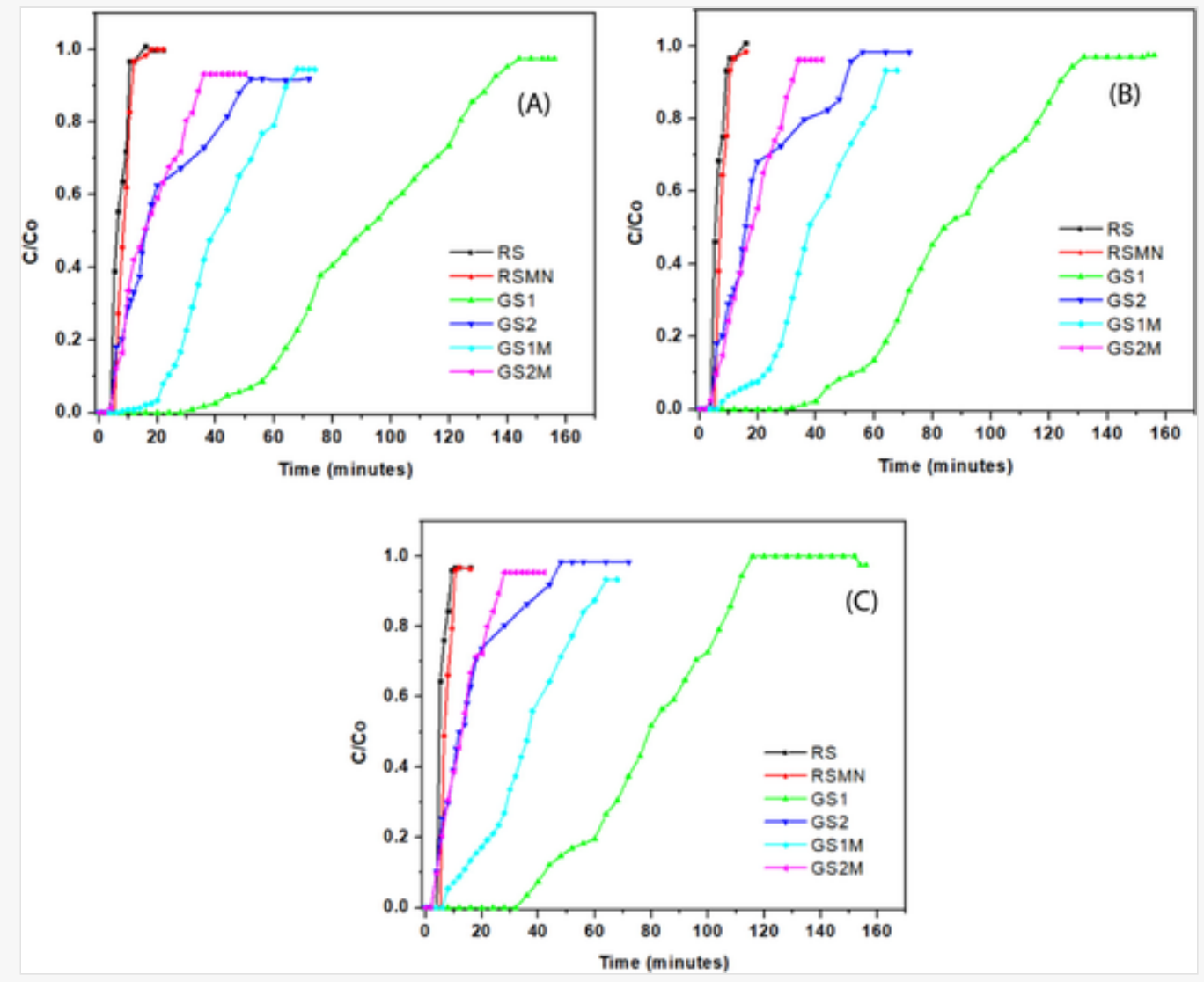
The breakthrough time for GS1 and GS1M was found to be significantly higher (5-12 times) than the rest filter materials as can be depicted from the above-stated values. The saturated adsorption capacity ( $\left.\mathrm{W}_{\text {sat }}\right)$ for all the sand composites are shown in Table 5 and has been compared for a total of three cycles of regenerated material. The $\mathrm{W}_{\text {sat }}$ value for GS1 and GS1M was found to be $18.6 \mathrm{mg} / \mathrm{kg}$ and $8.6 \mathrm{mg} / \mathrm{kg}$ while others showed the value of $<5 \mathrm{mg} / \mathrm{kg}$. In the second and third cycle of the regenerated material, $\mathrm{W}_{\text {sat }}$ values decreased for all the materials where the best performance was still carried by GS1 (reduced only by 14\%). The reusability of the sucrose (sugar) graphitized sand was found to be poor as the adsorption capacity decreased by $40 \%$ after 3 cycles of reuse (Table 5). All the six filters followed the bed-depth service time model (not shown here).

Overall, the graphitized sand showed a contrast in the adsorption characteristics for the source of sugars used for their synthesis. The adsorption parameters can also be related to an average MC-LR removal efficiency showed by GS2 (Fig. 6) as compared to GS1 where the latter was effective in nearly achieving the WHO guidelines. However, some future considerations must be accounted for the present study such as:

(a) A rigorous kinetics study for all the biofilters needs to be performed to know the adsorption behavior of MC-LR or other cyanotoxins.

(b) An experiment to explore the relationship between the surface charge of the adsorbents and $\mathrm{pH}$ can be performed to better understand the adsorbent properties.

(c) Other MC-LR-degraders, such as Rhodococcus sp., Brevibacterium sp., and Stenotrophomonas sp. must be tested for the bioaugmentation of the filters.

\section{Conclusion}

Brewery effluent used as a sugar source for sand graphitization performed better than the commercial sugar (sucrose) for most of the water contaminants (WCs) including organic carbon, nitrogen, and micropollutant: Microcystin-LR (MC-LR). Coating of manganese dioxide over raw sand increased the removal efficiency of various WQPs as compared to raw sand filters. In contrast, coating manganese oxide over the graphitized-sand (MOGS) was unable to enhance the removal efficiency of most WQPs including metals and MC-LR. Inoculation of screened MC-LR-degraders and native bacterial strains (isolated from drinking water plant: filtration unit) to different sand composite filters (graphitized or raw or MOGS) further enhanced the removal of the WQPs. Filter operation during inoculation stage showed 10\%-15\% higher MC-LR removal thereby suggesting favorable surface for the bacterial cells to proliferate and degrade MC-LR. All the sand composites were found to follow the Langmuir isotherm model and bed depth service time model for metal adsorption and breakthrough curve, respectively. Regeneration and reuse experiment showed fourteen times more breakthrough time for graphitized sand obtained from brewery effluent. The future application of the graphitized sand can be a household filter or as a replacement or conjugation of the sand media in a DWTPs. However, for the DWTP application, further work on the filtration rate and scale-up parameters needs to be performed adsorption before it can be applied. 


\section{Uncited references}

Asrafuzzaman et al. (2011), Mohan and Pittman (2007).

\section{Declaration of Competing Interest}

None.

\section{Acknowledgments}

The authors are sincerely thankful to the Natural Sciences and Engineering Research_Council of Canada (Discovery Grant 23451), and ATRAPP (Algal blooms, treatment, risk assessment, prediction, and prevention) for financial support (Genome Québec, Genome Canada; Grant 6116548-2015). Special thanks to Dana Simon for coordinating the sample receipt and analysis. Authors would also like to thank the team for constant support and timely suggestions. We want to thank Genome Quebec for timely sequencing of the bacterial identification. The views or opinions expressed in this article is exclusively those of the authors.

\section{Appendix A Supplementary material}

Supplementary data to this article can be found online at https://doi.org/10.1016/j.scitotenv.2019.135052.

\section{References}

(i) The corrections made in this section will be reviewed and approved by journal production editor.

Achazhiyath Edathil, A., Hisham Zain, J., Abu Haija, M., Banat, F., 2019. Scalable synthesis of an environmentally benign graphene-sand based organic-inorganic hybrid for sulfide removal from aqueous solution: an insight into the mechanism. New J. Chem. 43 (8), 3500-3512. doi:10.1039/c8nj05301d.

Alamri, S.A., 2012. Biodegradation of microcystin-RR by Bacillus flexus isolated from a Saudi freshwater lake. Saudi J. Biol. Sci. 19 (4), 435-440.

Ali, I., Al-Othman, Z.A., Alwarthan, A., Asim, M., Khan, T.A., 2013. Removal of arsenic species from water by batch and column operations on bagasse fly ash. Environ. Sci. Pollut. Res. 21 (5), 3218-3229.

Ali, I., Alothman, Z.A., Sanagi, M.M., 2015. Green synthesis of iron nano-impregnated adsorbent for fast removal of fluoride from water. J. Mol. Liq. 211, 457-465.

Ali, I., Al-Othman, Z.A., Al-Warthan, A., 2015. Removal of secbumeton herbicide from water on composite nanoadsorbent. Desalin. Water Treat. 57 (22), 10409-10421. 
Ali, I., Al-Othman, Z.A., Alharbi, O.M.L., 2016. Uptake of pantoprazole drug residue from water using novel synthesized composite iron nano adsorbent. J. Mol. Liq. 218, 465-472.

Ali, I., 2018. Microwave assisted economic synthesis of multi walled carbon nanotubes for arsenic species removal in water: Batch and column operations. J. Mol. Liq. 271, 677-685.

Ali, I., Alharbi, O.M.L., Alothman, Z.A., Alwarthan, A., 2018. Facile and eco-friendly synthesis of functionalized iron nanoparticles for cyanazine removal in water. Colloids Surf., B 171, 606-613.

APHA, AWWA, WPCF. 1998. Standard methods for the examination of water and wastewater, 19th Ed., Washington, D.C.

Asrafuzzaman, M., Fakhrudelin, A.N.M., Hossain, M.A., 2011. Redution of turbidity of water using

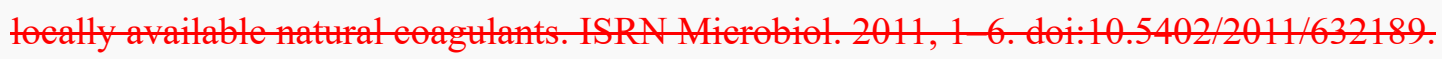

Bajpai, A.K., Dubey, R., Bajpai, J., 2017. Synthesis, characterization, and adsorption properties of a graphene composite sand (GCS) and its application in remediation of $\mathrm{Hg}(\mathrm{II})$ ions. Water Air Soil Pollut. 228(9). doi:10.1007/s11270-017-3511-5.

Bartel, H., Grützmacher, G., 2002. Elimination of microcystins by slow sand filtration at the UBA experimental field. In: Riverbank Filtration: Understanding Contaminant Biogeochemistry and Pathogen Removal, pp. 123-133.

Basheer, A.A., 2018. Chemical chiral pollution: Impact on the society and science and need of the regulations in the 21 st century. Chirality 30 (4), 402-406.

Basheer, A.A., 2018. New generation nano-adsorbents for the removal of emerging contaminants in water. J. Mol. Liq. 261, 583-593.

Boopathi, T., Ki, J.-S., 2014. Impact of environmental factors on the regulation of cyanotoxin production. Toxins (Basel) 6 (7), 1951-1978. doi:10.3390/toxins6071951.

Bourne, D.G., Blakeley, R.L., Riddles, P., Jones, G.J., 2006. Biodegradation of the cyanobacterial toxin microcystin LR in natural water and biologically active slow sand filters. Water Res. 40 (6), 1294-1302.

Chaudhry, S.A., Khan, T.A., Ali, I., 2016. Adsorptive removal of $\mathrm{Pb}$ (II) and $\mathrm{Zn}$ (II) from water onto manganese oxide-coated sand: Isotherm, thermodynamic and kinetic studies. Egypt. J. Basic Appl. Sci. 3 (3), 287-300. doi:10.1016/j.ejbas.2016.06.002.

Chusri, S., Sompetch, K., Mukdee, S., Jansrisewangwong, S., Srichai, T., Maneenoon, K., Voravuthikunchai, S.P., 2012. Inhibition of Staphylococcus epidermidis biofilm formation by traditional thai herbal recipes used for wound treatment. Evidence-Based Complementary Altern. Med. 2012, 1-8. doi:10.1155/2012/159797.

Davidson, J., Helwig, N., Summerfelt, S.T., 2008. Fluidized sand biofilters used to remove ammonia, biochemical oxygen demand, total coliform bacteria, and suspended solids from an intensive 
aquaculture effluent. Aquacult. Eng. 39 (1), 6-15. doi:10.1016/j.aquaeng.2008.04.002.

Dixit, F., Barbeau, B., Mohseni, M., 2018. Characteristics of competitive uptake between MicrocystinLR and natural organic matter (NOM) fractions using strongly basic anion exchange resins. Water Res. 139, 74-82. doi:10.1016/j.watres.2018.03.074.

Drogui, P., Daghrir, R., Simard, M.-C., Sauvageau, C., Blais, J.F., 2012. Removal of microcystin-LR from spiked water using either activated carbon or anthracite as filter material. Environ. Technol. 33 (4), 381-391.

Dubey, R., Bajpai, J., Bajpai, A.K., 2015. Green synthesis of graphene sand composite (GSC) as a novel adsorbent for efficient removal of Cr (VI) ions from aqueous solution. J. Water Process Eng. 5, 83-94. doi:10.1016/j.jwpe.2015.01.004.

Falconer, I.R., 2005. Is there a human health hazard from microcystins in the drinking water supply? Acta Hydroch. Hydrob. 33 (1), 64-71. doi:10.1002/aheh.200300551.

Falconer, I.R., 1999. An Overview of problems caused by toxic blue-green algae (cyanobacteria) in drinking and recreational water. Environ. Toxicol. 14 (1), 5-12. doi:10.1002/(sici)15227278(199902)14:1<5::Aid-tox3>3.0.Co;2-0.

Fayad, P., B., Roy-Lachapelle, A., Duy, S. V., Prévost, M., \& Sauvé, S., 2015. On-line solid-phase extraction coupled to liquid chromatography tandem mass spectrometry for the analysis of cyanotoxins in algal blooms. Toxicon 108, 167-175. doi:10.1016/j.toxicon.2015.10.010.

Fortune, W.B., Mellon, M.G., 1938. Determination of iron with o-phenanthroline: a spectrophotometric study. Ind. Eng. Chem. Anal. Ed. 10 (2), 60-64. doi:10.1021/ac50118a004.

Gupta, T. S. Sreeprasad, S. M. Maliyekkal, S. K. Das and T. Pradeep, 2012. Graphene from Sugar and its Application in Water Purification. ACS Applied Materials \& Interfaces 4 (8), 4156-4163. doi:10.1021/am300889u.

Haider, S., Naithani, V., Viswanathan, P.N., Kakkar, P., 2003. Cyanobacterial toxins: a growing environmental concern. Chemosphere 52 (1), 1-21.

Hallé, C., Huck, P.M., Peldszus, S., 2015. Emerging contaminant removal by biofiltration: temperature, concentration, and EBCT impacts. J. - Am. Water Works Assoc. 107 (7), E364-E379.

Hameed, B., Din, A., Ahmad, A., 2007. Adsorption of methylene blue onto bamboo-based activated carbon: Kinetics and equilibrium studies. J. Hazard. Mater. 141 (3), 819-825. doi:10.1016/j.jhazmat.2006.07.049.

Healy, M.G., Rodgers, M., Mulqueen, J., 2007. Performance of a stratified sand filter in removal of chemical oxygen demand, total suspended solids and ammonia nitrogen from high-strength wastewaters. J. Environ. Manage. 83 (4), 409-415. doi:10.1016/j.jenvman.2006.03.005. 
Ho, L., Meyn, T., Keegan, A., Hoefel, D., Brookes, J., Saint, C.P., Newcombe, G., 2006. Bacterial degradation of microcystin toxins within a biologically active sand filter. Water Res. 40 (4), 768-774. doi:10.1016/j.watres.2005.12.009.

Ho, L., Hoefel, D., Saint, C.P., Newcombe, G., 2007. Degradation of Microcystin-LR through biological sand filters. Practice Periodical Hazard., Toxic, Radioactive Waste Manage. 11 (3), 191-196. doi:10.1061/(asce)1090-025x(2007) 11:3(191).

Ho, L., Lambling, P., Bustamante, H., Duker, P., Newcombe, G., 2011. Application of powdered activated carbon for the adsorption of cylindrospermopsin and microcystin toxins from drinking water supplies. Water Res. 45 (9), 2954-2964.

Huang, W.-J., Cheng, B.-L., Cheng, Y.-L., 2007. Adsorption of microcystin-LR by three types of activated carbon. J. Hazard. Mater. 141 (1), 115-122.

Hu, L., Zhang, F., Liu, C., Wang, M., 2012. Biodegradation of Microcystins by Bacillus sp. strain EMB. Energy Procedia 16, 2054-2059.

Jenkins, M.W., Tiwari, S.K., Darby, J., 2011. Bacterial, viral and turbidity removal by intermittent slow sand filtration for household use in developing countries: Experimental investigation and modelling. Water Res. 45 (18), 6227-6239. doi:10.1016/j.watres.2011.09.022.

Jia, H., Liu, J., Zhong, S., Zhang, F., Xu, Z., Gong, X., Lu, C., 2015. Manganese oxide coated river sand for $\mathrm{Mn}(\mathrm{II})$ removal from groundwater. J. Chem. Technol. Biotechnol. 90 (9), 1727-1734. doi:10.1002/jctb.4524.

Keijola, A.M., Himberg, K., Esala, A.L., Sivonen, K., Hiis-Virta, L., 1988. Removal of cyanobacterial toxins in water treatment processes: Laboratory and pilot-scale experiments. Toxicity Assessment 3 (5), $643-656$.

Kumar, P., Hegde, K., Brar, S.K., Cledon, M., Kermanshahi-pour, A., Roy-Lachapelle, A., GalvezCloutier, R., 2018. Biodegradation of microcystin-LR using acclimatized bacteria isolated from different units of the drinking water treatment plant. Environ. Pollut. 242, 407-416. doi:10.1016/j.envpol.2018.07.008.

Kumar, P., Rubio, H.D.P., Hegde, K., Brar, S.K., Cledon, M., Kermanshahi-pour, A., Galvez-Cloutier, R., 2019. Agro-industrial residues as unique support in a sand filter to enhance the bioactivity to remove microcystin-Leucine aRginine and organics. Sci. Total Environ. 670, 971-981. doi:10.1016/j.scitotenv.2019.03.260.

Lai, C.H., Chen, C.Y., 2001. Removal of metal ions and humic acid from water by iron-coated filter media. Chemosphere 44 (5), 1177-1184.

Manage, P.M., Edwards, C., Singh, B.K., Lawton, L.A., 2009. Isolation and identification of novel microcystin-degrading bacteria. Appl. Environ. Microbiol. 75 (21), 6924-6928. 
Mehlig, J., 1941. Colorimetric determination of copper with ammonia. Ind. Eng. Chem. Anal. Ed. 13 (8), 533-535. doi:10.1021/i560096a006.

Mo, J., Yang, Q., Zhang, N., Zhang, W., Zheng, Y., Zhang, Z., 2018. A review on agro-industrial waste (AIW) derived adsorbents for water and wastewater treatment. J. Environ. Manage. 227, 395-405.

Mohan, D., Pittman, C.U., 2007. Arsenic removal from water/wastewater using adsorbents A critical review. J. Hazard. Mater. 142 ( 1 2 2), 1 53. doi:10.1016/j.jhazmat.2007.01.006.

Rachmawati, S., Tizaoui, C., Hilal, N., 2013. Manganese coated sand for copper (II) removal from water in batch mode. Water 5 (4), 1487-1501.

Rahman, S., Praseetha, P.K., 2016. Analysis of water purification efficiency of graphene sand nanocomposite. Int. J. Eng. Res. Afr. 24, 17-25. doi:10.4028/www.scientific.net/JERA.24.17.

Somdee, T., Thunders, M., Ruck, J., Lys, I., Allison, M., Page, R., 2013. Degradation of [Dha7]MC-LR by a microcystin degrading bacterium isolated from Lake Rotoiti, New Zealand. ISRN Microbiol. 2013, 1-8.

Tesfaldet, Z., 2004. Spectrophotometric determination of magnesium in pharmaceutical preparations by cost-effective sequential injection analysis. Talanta 64 (4), 981-988. doi:10.1016/j.talanta.2004.04.026.

Unger, M., Collins, M.R., 2008. Assessing Escherichia coli removal in the schmutzdecke of slow-rate biofilters. J. - Am. Water Works Assoc. 100 (12), 60-73. doi:10.1002/j.1551-8833.2008.tb09799.x.

Zhang, Y., Zhu, H., Szewzyk, U., Lübbecke, S., Uwe Geissen, S., 2017. Removal of emerging organic contaminants with a pilot-scale biofilter packed with natural manganese oxides. Chem. Eng. J. 317 , 454-460.

Zularisam, A.W., Wahida, N., Alfian, A., 2017. Comparison on characteristic of Mesoparticle Graphene Sand Composite (MGSC) using different types of sugar to remove methylene blue. IOP Conf. Ser.: Mater. Sci. Eng. 217. doi:10.1088/1757-899x/217/1/012005.

\section{Graphical abstract}




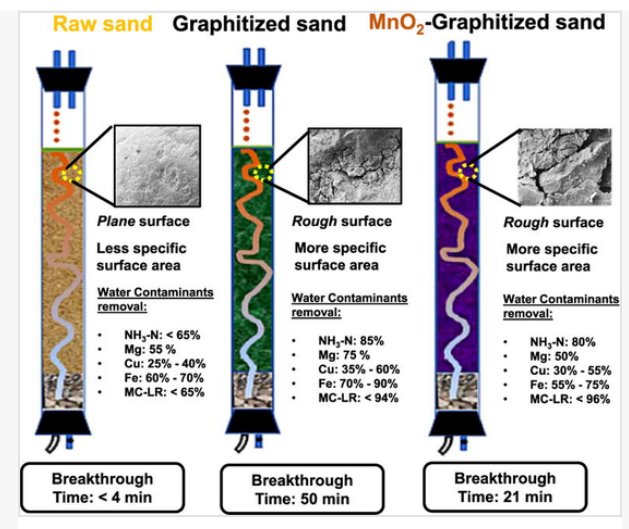

\section{Highlights}

- Graphitized sand showed highest removal for Iron and Magnesium metal ions.

- $\mathrm{MnO}_{2}$-coated graphitized sand performed best (>95\%) in terms of MC-LR removal.

- Graphitized sand (GS1) synthesized from brewery effluent showed highest breakthrough time.

- Principal component analysis showed GS1 as the best filter.

- Inoculation of MC-LR-degraders in filters further enhanced their performance.

\section{Appendix A Supplementary material}

The following are the Supplementary data to this article:

Multimedia Component 1

Supplementary data 1

Multimedia Component 2

Supplementary data 2

\section{Queries and Answers}

Query: Your article is registered as a regular item and is being processed for inclusion in a regular issue of the journal. If this is NOT correct and your article belongs to a Special Issue/Collection please contact p.das@elsevier.com immediately prior to returning your corrections.

Answer: Yes, it is a regular item. 
Query: The author names have been tagged as given names and surnames (surnames are highlighted in teal color).

Please confirm if they have been identified correctly.

Answer: Yes, they are identified correctly.

Query: The country name has been inserted for the affiliations ' $b$ and g'. Please check, and correct if necessary.

Answer: All ok.

Query: Please check the address for the corresponding author that has been added here, and correct if necessary. Answer: Correct.

Query: Please check the hierarchy of the section headings.

Answer: Checked. It is ok.

Query: Please check all the reference citations in the text, and correct if necessary.

Answer:

Query: Ref(s). Bartel et al. (2002), Gupta et al. (2012), Naghdi et al. (2017), Fayad et al. (2015) are cited in the text but not provided in the reference list. Please provide them in the reference list or delete these citations from the text.

Answer: In the text, I have corrected the reference author for Bartel. It is not Bartel et al, it is Bartel and Grumzmacher. ALso, the other three references namely, Fayad et al. 2015, Gupta et al., 2012 is added. Naghdi et al can be deleted, in place, we have added another article: Kumar et al. 2019, this reference was already in the reference list (Kumar et al., 2019).

Query: Please check the edit(s) made in Table 4, and correct if necessary.

Answer:

Query: Uncited references: This section comprises references that occur in the reference list but not in the body of the text. Please cite each reference in the text or, alternatively, delete it. Any reference not dealt with will be retained in this section.

Answer: References now deleted fromt he reference list.

Query: Have we correctly interpreted the following funding source(s) and country names you cited in your article: Natural Sciences and Engineering Research, Canada? /

Answer: I HAVE CORRECTED IT . 
